\author{
UNIVERSIDADE DE SÃO PAULO \\ FACULDADE DE CIÊNCIAS FARMACÊUTICAS DE RIBEIRÃO PRETO \\ CAMILA ALESSANDRA MINI
}

Estabelecimento de um modelo de epiderme em 3D proveniente de células imortalizadas a ser utilizado como plataforma de avaliação da toxicidade dérmica induzida por corantes de tinturas capilares 


\title{
Estabelecimento de um modelo de epiderme em 3D proveniente de células imortalizadas a ser utilizado como plataforma de avaliação da toxicidade dérmica induzida por corantes de tinturas capilares
}

\author{
Tese de Doutorado apresentada ao programa de \\ Pós-Graduação em Toxicologia da Faculdade de \\ Ciências Farmacêuticas de Ribeirão Preto/USP \\ para obtenção do Título de Doutor em Ciências. \\ Área de Concentração: Toxicologia \\ Orientadora: Danielle Palma de Oliveira \\ Co-orientadora: Silvya Stuchi Maria-Engler
}

Versão corrigida da Tese de Doutorado apresentada ao Programa de Pós-Graduação em Toxicologia em 12/08/2020. A versão original encontra-se disponível na Faculdade de Ciências Farmacêuticas de Ribeirão Preto/USP. 
Autorizo a reprodução e divulgação total ou parcial deste trabalho, por qualquer meio convencional ou eletrônico, para fins de estudo e pesquisa, desde que citada a fonte.

Mini, Camila Alessandra

Estabelecimento de um modelo de epiderme 3D proveniente de células imortalizadas a ser utilizado como plataforma de avaliação da toxicidade dérmica induzida por corantes de tinturas capilares. Ribeirão Preto, 2020.

103 p. : il. ; $30 \mathrm{~cm}$

Tese de Doutorado, apresentada à Faculdade de Ciências Farmacêuticas de Ribeirão Preto/USP. Área de concentração: Toxicologia.

Orientador: Oliveira, Danielle Palma de.

Co-orientador: Maria Engler, Silvya Stuchi

1-Epiderme Humana Equivalente. 2-Células HaCaT. 3-Exposição dérmica. 4-Genotoxicidade. 5-Citotoxicidade. 6- Irritação. 7-Corrosão 


\section{RESUMO}

MINI, C. A. Estabelecimento de um modelo de epiderme em 3D proveniente de células imortalizadas a ser utilizado como plataforma de avaliação da toxicidade dérmica induzida por corantes de tinturas capilares. 2020 103f. Tese (Doutorado). Faculdade de Ciências Farmacêuticas de Ribeirão Preto- Universidade de São Paulo, Ribeirão Preto, 2020.

Com a adoção de métodos alternativos ao uso de animais na comunidade científica, diversos grupos trabalharam para o desenvolvimento de novos modelos capazes de ser aplicados na avaliação da toxicidade de substâncias/produtos. Tratando-se de exposição dérmica, os modelos de pele/epiderme reconstruída foram desenvolvidos no mundo todo, porém a aquisição desses modelos no Brasil é bastante dificultosa. Devido a isso, o objetivo aqui proposto foi o desenvolvimento de um modelo tridimensional de epiderme, utilizando queratinócitos imortalizados (HaCaT-EHE) para aplicação na avaliação de toxicidade de corantes presentes em tinturas capilares, além da comparação dos efeitos com a cultura celular em monocamada. Após a construção do modelo tridimensional, foi avaliada a diferenciação celular por métodos histológicos/imunohistoquímicos, validação do método analítico de determinação do sal de formazan utilizado nos testes de corrosão e irritação. Foi verificada a permeabilidade da membrana e proficiência do modelo em diferenciar substâncias irritantes, não irritantes, corrosivas e não corrosivas. Para avaliação de endpoints de toxicidade foram realizados ensaio de genotoxicidade (ensaio do Cometa), viabilidade/citotoxicidade (MTT, teste de viabilidade celular por anexina V/PI e teste de Tunel) e irritação e corrosão. O modelo apresentou diferenciação celular e expressão dos biomarcadores de desenvolvimento das camadas, além disso apresentou permeabilidade de membrana semelhante aos modelos já validados. O método para a determinação do sal de formazan mostrou ser seletivo, exato, preciso e robusto. Além disso, apresentou um índice de recuperação superior a $85 \%$ e variação inferior a $15 \%$, e não foi observada a presença resíduos do sal após uma injeção com concentração elevada. Adicionalmente, o modelo demonstrou boa predição para irritação (seletividade 100\%, especificidade $75 \%$ e exatidão $90 \%$ ) e também para corrosão (seletividade 100\%, especificidade $100 \%$ e exatidão 100\%) para as substâncias testadas. Quanto aos corantes, o Basic Blue 99 (BB99) não demonstrou efeitos genotóxicos em ambos modelos, porém, demonstrou queda na viabilidade celular, além de intensa marcação com PI e dupla marcação (anexina e PI) indicando morte celular por necrose no modelo 2D. No modelo 3D, observou-se intensa marcação com fluoresceína em todas as concentrações testadas, indicando ocorrência apoptose. Como esperado, o BB99 se mostrou irritante após a exposição por 30 minutos, embora não tenha induzido a efeito corrosivo. Já o corante Basic Red 51 (BR51) induziu a efeitos genotóxicos em ambos os modelos, além disso provocou queda na viabilidade celular no modelo $2 \mathrm{D}$ e no modelo $3 \mathrm{D}$ induziu a marcação com a fluoresceína. O corante não apresentou efeitos irritantes e corrosivos. Frente ao exposto, podemos concluir que o modelo apresentou boa predição e pode ser utilizado como plataforma de estudos de avaliação da segurança/toxicidade de produtos após a exposição dérmica. Os corantes testados demonstraram efeitos tóxicos em concentrações inferiores ao limite recomendado pelo Comitê Científico Europeu e, desta forma, a utilização em produtos comerciais de tinturas capilares deveria ser revista.

Palavras-chave: Epiderme Humana Equivalente. Células HaCaT. Exposição dérmica. Genotoxicidade. Citotoxicidade. Irritação. Corrosão. 


\begin{abstract}
MINI, C. A. Establishment of a tested 3D epidermis model of an immortalized cells as a platform for assessing dermal toxicity induced by hair dyes. 2020. 103f. Thesis (Doctoral). Faculdade de Ciências Farmacêuticas de Ribeirão Preto, 2020.
\end{abstract}

With the adoption of alternative methods to the use of animals in the scientific community, several groups worked towards the development of new models capable of being applied in the evaluation of the toxicity of substances / products. In the case of dermal exposure, the reconstructed skin / epidermis models were developed worldwide, but the acquisition of these models in Brazil is quite difficult. Because of this, the objective proposed here was the development of a three-dimensional model of epidermis, using immortalized keratinocytes (HaCaT-EHE) for application in the evaluation of toxicity of dyes present in hair dyes, in addition to comparing the effects with cell culture in monolayer . After building the threedimensional model, cell differentiation was evaluated by histological / immunohistochemical methods, validation of the analytical method for determining formazan salt used in corrosion and irritation tests. The permeability of the membrane and the proficiency of the model in differentiating irritating, non-irritating, corrosive and non-corrosive substances were verified. For evaluation of toxicity endpoints, genotoxicity assay (Comet assay), viability / cytotoxicity (MTT, cell viability test by annexin V / PI and Tunel test) and irritation and corrosion were performed. The model showed cell differentiation and expression of the biomarkers of development of the layers, in addition it presented membrane permeability similar to the models already validated. The method for determining formazan salt has proven to be selective, accurate, precise and robust. In addition, it had a recovery rate greater than $85 \%$ and variation less than 15\%, and the presence of salt residues was not observed after an injection with high concentration. In addition, the model demonstrated good prediction for irritation (100\% selectivity, $75 \%$ specificity and $90 \%$ accuracy) and also for corrosion (100\% selectivity, 100\% specificity and 100\% accuracy) for the tested substances. As for the dyes, Basic Blue 99 (BB99) did not demonstrate genotoxic effects in both models, however, it showed a decrease in cell viability, in addition to intense staining with PI and double staining (annexin and PI) indicating cell death by necrosis in the $2 \mathrm{D}$ model. In the 3D model, intense fluorescein staining was observed at all concentrations tested, indicating apoptosis. As expected, BB99 was irritating after exposure for 30 minutes, although it did not induce a corrosive effect. The Basic Red 51 (BR51) dye induced genotoxic effects in both models, in addition it caused a drop in cell viability in the 2D model and in the 3D model it induced fluorescein staining. The dye had no irritating or corrosive effects. In view of the above, we can conclude that the model presented a good prediction and can be used as a platform for evaluating the safety / toxicity of products after dermal exposure. The dyes tested demonstrated toxic effects at concentrations below the limit recommended by the European Scientific Committee and, therefore, the use in commercial hair dye products should be reviewed.

Keywords: Equivalent Human Epidermis. HaCaT cells. Dermal exposure. Genotoxicity. Cytotoxicity. Irritation. Corrosion. 
INTRODUÇÃO 


\section{INTRODUÇÃO}

A frase do filósofo e dramaturgo romano Plautus (254-184 a.C.) embora muito antiga, revela a necessidade da população em geral de fazer uso de cosméticos para melhorar a autoestima: "Uma mulher sem tinta é como comida sem sal" (COSMETICS INFO, 2016). De acordo com o Food Drug Administration (FDA/E.U.A.), os cosméticos são substâncias que podem ser passadas, derramadas, polvilhadas, pulverizadas e aplicadas ao corpo humano para a limpeza, embelezamento e alteração da aparência (FDA, 2018a), sendo estes dois últimos, os principais motivos que fizeram o sucesso da indústria mundial de cosméticos.

Além dos cosméticos convencionais, há uma subclassificação denominada “cosmecêuticos" que são bastante utilizados. Esses produtos além da função principal, possuem ingredientes na formulação que podem trazer outros benefícios para o indivíduo que os usa, como por exemplo cremes hidratantes anti-idade, xampu anti-caspa, cremes anti-acne entre outros (MILAM; RIEDER, 2016).

Assim, a intensa busca por uma aparência que atenda aos padrões sociais promove uma grande procura de procedimentos estéticos diversos, acarretando o uso exacerbado de cosméticos. A Associação Brasileira da Indústria de Higiene Pessoal, Perfumaria e Cosméticos (ABIHPEC) mostrou em seu relatório mais recente que os maiores consumidores dos produtos do setor no mundo são os Estados Unidos, China, Japão e o Brasil (ABIHPEC, 2019).

Dentro desse contexto, o uso excessivo desses produtos, associado à intensa evolução das indústrias cosméticas, que lançam constantemente novos produtos, claramente demonstra a necessidade da avaliação da segurança, tanto das matérias primas como dos produtos finais. Soma-se a estes fatos, o uso rotineiro de uma grande variedade de cosméticos por uma significativa parcela da população, reforçando assim, a necessidade de uma completa avaliação dos efeitos que os componentes das fórmulas e o produto finalizado podem provocar quando entram em contato com a pele, olhos, couro cabeludo, unhas etc.

Por muito tempo, a avaliação da toxicidade de produtos de higiene e beleza foi realizada basicamente utilizando testes em animais. No entanto, a partir do início dos anos 2000, a União Europeia iniciou um movimento para substituição dos ensaios em animais, para a avaliação da segurança de cosméticos e outros componentes presentes nas fórmulas, culminando na completa proibição em 2009, com a publicação da Diretiva 1223/2009 (EC, 2009; 
SCCS/1564/15). Desta forma, os laboratórios europeus foram pioneiros no desenvolvimento e validação de métodos alternativos à experimentação animal, permitindo o uso na avaliação da segurança de cosméticos. Esta tendência foi difundida para a avaliação de diversos outros produtos com aplicações variadas, com o objetivo de reduzir o número de animais na avaliação inicial da toxicidade, atendendo ao conceito dos 3R de acordo com Russel e Burch o qual será discutido adiante, diminuindo assim o número de compostos que são encaminhados para a avaliação completa da toxicidade, como nos ensaios pré-clínicos.

Assim, o desenvolvimento de métodos alternativos tem sido considerado uma grande tendência mundial na área da Toxicologia, demonstrado pelo grande interesse na discussão deste tema nos eventos científicos da área.

Atualmente, diversos trabalhos demonstram que métodos in vitro podem ser preditivos e a substituição e/ou redução no uso de animais pode ser realizada sem colocar em risco a confiança dos resultados. A importância na substituição não é apenas por resultados confiáveis, mas pelo fator econômico envolvido, considerando que a manutenção de animais em biotério é de custo elevado além do tempo envolvido na pesquisa, afinal muitos testes in vitro garantem respostas em um período mais curto (HIRSCH; SCHILDKNECHT, 2019).

Dentro deste contexto, a evolução na ciência não apenas garante a utilização de novos modelos e métodos, mas possibilita segurança nos produtos utilizados e atende a política dos 3R's que desde a década de 50, revolucionou o conceito da utilização dos animais na indústria e pesquisa.

\subsection{Tinturas de cabelo}

O Brasil é o $4^{\circ}$ maior consumidor de produtos de Higiene Pessoal, Perfumaria e Cosméticos, perdendo apenas para os Estados Unidos, China e Japão. Embora, o consumo de produtos tenha enfrentado uma queda nos últimos anos devido à crise financeira, o setor vinha apresentando sinais de recuperação em 2019 (ABIHPEC, 2019). No entanto, devido a atual pandemia devido ao SARS-COV-2, alguns especialistas apontam para uma crise no comércio global, tendo já sido constatada uma queda de aproximadamente $15 \%$ nas vendas de produtos de beleza no mês de março de 2020, provavelmente devido ao fato das pessoas estarem em isolamento social e, portanto, se preocupando menos com a aparência. Soma-se a isso o fechamento de salões de beleza devido aos decretos governamentais que impedem o 
funcionamento de alguns estabelecimentos (ABIHPEC, 2020a; ABIHPEC, 2020b; AGÊNCIA BRASIL, 2020).

Ainda assim, o setor de cosméticos é um ramo muito forte da economia brasileira. Segundo o relatório da Associação Brasileira da Indústria de Higiene Pessoal, Perfumaria e Cosméticos (ABIHPEC), a necessidade de autorrealização é o principal motivo para que os indivíduos utilizem produtos de higiene, perfumes e cosméticos, demonstrando que os brasileiros estão cada vez mais visando o bem-estar pelo uso desses produtos (ABIHPEC, 2019).

Dentre esses produtos, as tinturas capilares representam grande destaque no ramo industrial, ocupando a $4^{\text {a }}$ colocação entre os cosméticos mais utilizados pelos brasileiros (ABIHPEC, 2019). Essa intensa utilização provavelmente é devida ao fato de que as tinturas capilares estão entre os produtos cosméticos de maior potencial de modificação da autoimagem. No Brasil, um quarto da população já realizou algum tipo de procedimento de coloração pelo menos uma vez na vida (INMETRO, 2006).

A indústria produtora de tinturas começou quando Hoffman descobriu, em 1863, a coloração marrom produzida pela parafenilenodiamina (PPD) após uma reação de oxidação. Em 1907, Eugene Schueller, fundador da L'Oreal lançou a primeira marca de tinturas de cabelo que era de uso restrito aos salões de beleza até a década de 50. Porém, com os avanços na tecnologia, várias tinturas de uso doméstico foram lançadas posteriormente e, rapidamente seu uso foi disseminado na população (DRAELOS, 2004).

As tinturas de cabelos são classificadas de acordo com o modo de fixação na fibra capilar, podendo ser fixadas na cutícula ou no córtex por mecanismos oxidativos ou não oxidativos. Nas reações oxidativas, a cutícula do fio é aberta com a ação dos agentes alcalinizantes (amônia), permitindo a penetração do precursor e do peróxido de hidrogênio no fio. Com a penetração dos compostos, ocorre a reação de oxidação, promovendo assim a alteração permanente da cor do fio (SANÍA; CARREÑO, 2007; MADNANI; KHAN, 2013).

Já os mecanismos não oxidativos compreendem os corantes de cabelos diretos, que independem de reações oxidativas e se fixam diretamente no fio por ligações químicas fracas. Esses corantes compõem geralmente as fórmulas de colorações semi-permanentes e temporárias (SANÍA; CARREÑO, 2007).

Outra classificação comum das tinturas leva em consideração o tempo de permanência da cor no fio como se segue: 
a) Temporárias: representam apenas 3\% dos tipos de coloração. São facilmente removidas pela lavagem, pois são compostas por moléculas mais pesadas, tornando-as incapazes de penetrar no córtex. Desta forma, o corante fica apenas depositado na cutícula por meio de ligação a um polímero catiônico que aumenta a afinidade do corante pelo fio (Figura 1A) (DRAELOS, 2004; GUERRA-TAPIA; GONZALEZ-GUERRA, 2014; ACS, 2019).

b) Demi-permanente: representam cerca de $10 \%$ dos produtos, mas não são encontrados em fórmulas profissionais, devido a ineficácia em cobrir fios grisalhos. São produtos que contém corantes do grupo azo e nitroanilina principalmente e são capazes de aumentar o brilho e fornecer uma mudança leve na tonalidade da cor. Neste caso, o corante adere ao fio de cabelo por ligações polares fracas e por força de Van der Waals, e duram cerca de 6 a 8 lavagens. (Figura 1 B) (DRAELOS, 2004; GUERRA-TAPIA; GONZALEZ-GUERRA, 2014; ACS, 2019):

c) Permanente: é o tipo de coloração mais comum e mais utilizado, representando cerca de $85 \%$ das tinturas comercializadas. As substâncias químicas tais como parafenilenodiamina, paratoluenodiamina e resorinol são precursores e/ou acopladores e revelam a cor após uma reação de oxidação provocada pelo peróxido de hidrogênio. São $100 \%$ eficientes na cobertura de cabelos grisalhos e, devido ao baixo peso molecular, são capazes de penetrar completamente no córtex do fio promovendo a alteração definitiva da cor natural. Desta forma, a lavagem não consegue remover as substâncias e a manutenção da cor é feita pelo retoque na raiz quando ocorre o crescimento do fio (Figura 1C) (DRAELOS, 2004; GUERRA-TAPIA; GONZALEZ-GUERRA, 2014; ACS, 2019).

d) Descolorante: substâncias capazes de promover descoloração permanente do fio por meio da utilização de amônia e peróxido de hidrogênio ocorrendo a oxidação da melanina do fio (DRAELOS, 2004; GUERRA-TAPIA; GONZALEZ-GUERRA, 2014).

No Brasil há apenas uma legislação que regulamenta a inserção de corantes nas formulações das tinturas, porém não há legislação para os corantes abordados neste trabalho (BRASIL, 2012). 
Figura 1 - Representação da penetração dos corantes presentes nas tinturas no fio capilar.

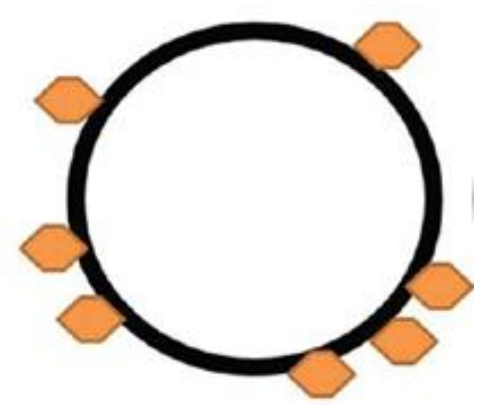

Tinturas Temporárias

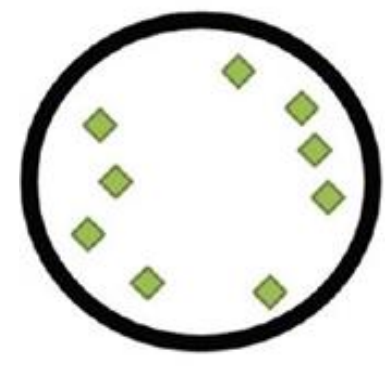

B)

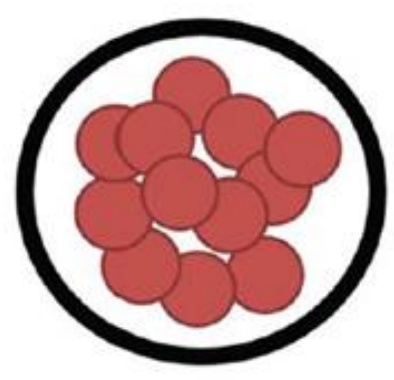

Tinturas

permanentes

C)

Fonte: Adaptação Madnani; Khan (2013).

A) Tinturas temporárias com ligação superficial e externa ao fio; B) Tinturas semipermanentes com ligação superficial e interna no fio; $C$ ) tinturas permanentes com ligação mais profunda e interna no fio.

Frente ao exposto, fica claro que o processo de tingimento depende da anatomia dos fios, que são compostos essencialmente por 3 camadas (Figura 2): a cutícula, o córtex e medula (BUFFOLI et al., 2014).

Figura 2- Representação da estrutura do fio de cabelo

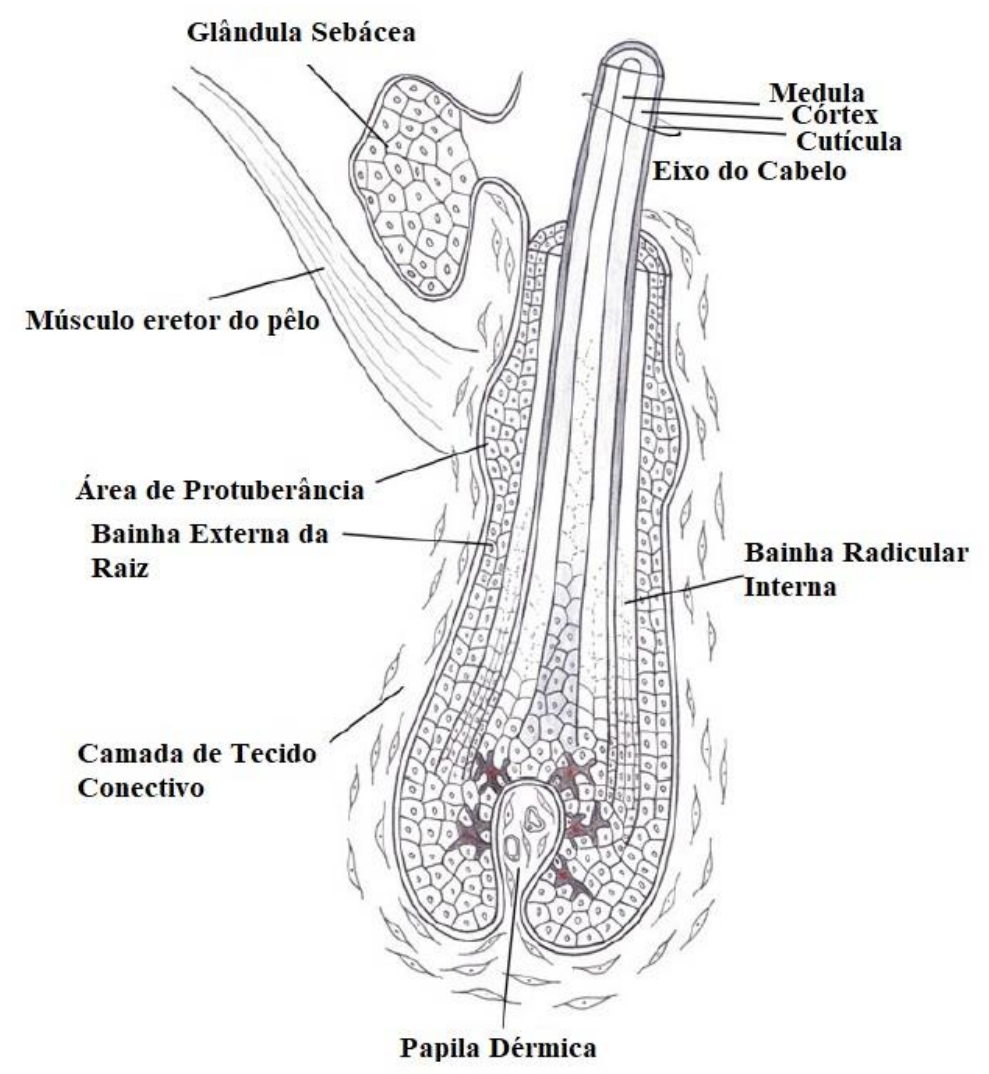

Fonte: Adaptação Buffoli et al. (2014) 
Apesar do uso rotineiro desses produtos, de acordo com a International Agency Research on Cancer (IARC), alguns compostos presentes nesses produtos podem apresentar efeitos carcinogênicos em decorrência da exposição. Dentre esses compostos tóxicos, estão substâncias que contém o grupamento azo $(\mathrm{N}=\mathrm{N})$ e aminas aromáticas (IARC, 2010). Considerando que a anatomia do fio favorece a absorção de algumas substâncias através do folículo piloso (BUFOLLI et al., 2014), a manifestação de efeitos sistêmicos após a aplicação tópica durante o processo de tintura pode ocorrer. Já foi apontada uma possível correlação entre a exposição aos corantes e/ou outros componentes da formulação, como o-toluidina e anilina, com o desenvolvimento de alguns tipos de cânceres como bexiga, mama e linfoma (WARD et al., 1996; VINEIS; PIRASTU, 1997; NCI, 2016; GERA et al., 2018; ACS, 2019). Adicionalmente, a utilização de tinturas de cabelo também já foi relacionada a manifestação de irritação da pele, sensibilização e alergias (KIM; KABIR; JAHAN, 2016; ZANONI et al., 2017).

Por outro lado, outros trabalhos sugerem que tinturas mais modernas não provocam riscos ou efeitos genotóxicos e mutagênicos no organismo, e que o risco sistêmico é baixo (NOHYNEK et al., 2010; ZANONI et al, 2014; ZANONI et al., 2015; KIM; KABIR; JAHAN, 2016; JIANN, 2017). Assim, fica evidente que não existe consenso a respeito dos riscos associados à exposição aos corantes, demonstrando a necessidade de novos estudos.

Desde 1965, a IARC demonstrou preocupação com as substâncias potencialmente carcinogênicas em diversos produtos, ressaltando a importância dos estudos para avaliação toxicológica (IARC, 2010). A interação dos agentes químicos com o material genético pode acarretar lesões no DNA, ou seja, efeitos genotóxicos e quando essas lesões não são reparadas, ocorre uma mutação e essa informação será transmitida para as células filhas no momento da divisão. Alguns corantes de cabelo são capazes de induzir lesões no DNA, que podem ser detectadas pelo ensaio do cometa (TARFUT-CARDONA et al., 2015). Neste sentido, no presente trabalho estudamos dois corantes amplamente empregados em formulações de tinturas comerciais, o Basic Red 51 (BR51) e Basic Blue (BB99) (Figura 3). Ambos são geralmente encontrados em tinturas semi-permanentes, mas o BR51 também compõe algumas formulações de tinturas permanentes. 
Figura 3- Estrutura química dos corantes Basic Red 51 (A) e Basic Blue 99 (B)<smiles>CN(C)c1ccc(N=Nc2n(C)cc[n+]2C)cc1</smiles><smiles>C[N+](C)(C)c1cccc(Nc2cc(N)c3c(c2O)C(=N)C=C(Br)C3=O)c1</smiles>

Nosso grupo de pesquisa vem estudando o corante BR51, demonstrado a indução de espécies reativas do oxigênio (ZANONI et al., 2014) e alterações morfológicas nas células de pele (ZANONI et al., 2015). O BB99 foi estudado por Franco et al. (2015), que detectaram o corante na água de lavagem, mesmo após 5 procedimentos, demonstrando a permanência e, consequente exposição das células do couro cabeludo por longo período, após um processo rotineiro de tintura (FRANCO et al., 2015).

Os resultados já obtidos em cultura celular em monocamada reiteram à necessidade de avaliar os corantes em ambiente 3D de epiderme, para avaliação da resposta e comparação com os resultados dos ensaios realizados com cultura celular tradicional.

\subsection{Anatomia da pele}

O tecido tegumentar é o maior órgão do corpo humano, composto por três camadas principais denominadas epiderme, derme e hipoderme. A atuação como barreira física está dentre as principais funções da pele e a sua eficiência é devida a presença de lipídeos no espaço intercelular dos queratinócitos presentes na epiderme. Além disso, a pele é também responsável pela manutenção da homeostase térmica, ação sensorial e função imunológica (WHO, 2009; VENUS; WATERMAN; McNAB, 2011; YOUSEF; ALHAJJ;SHARMA, 2020). Além disso, 
acredita-se que a epiderme além da função de barreira física contra substâncias tóxicas, apresenta também funções fisiológicas capazes de auxiliar nos mecanismos de defesa após a exposição a diversos estressores externos (SCCS, 2015).

A Figura 4 mostra as duas camadas mais superficiais da pele, derme e epiderme, assim como alguns dos anexos, como vasos sanguíneos e glândulas.

Figura 4- Representação anatômica das camadas mais superficiais da pele, derme e epiderme.

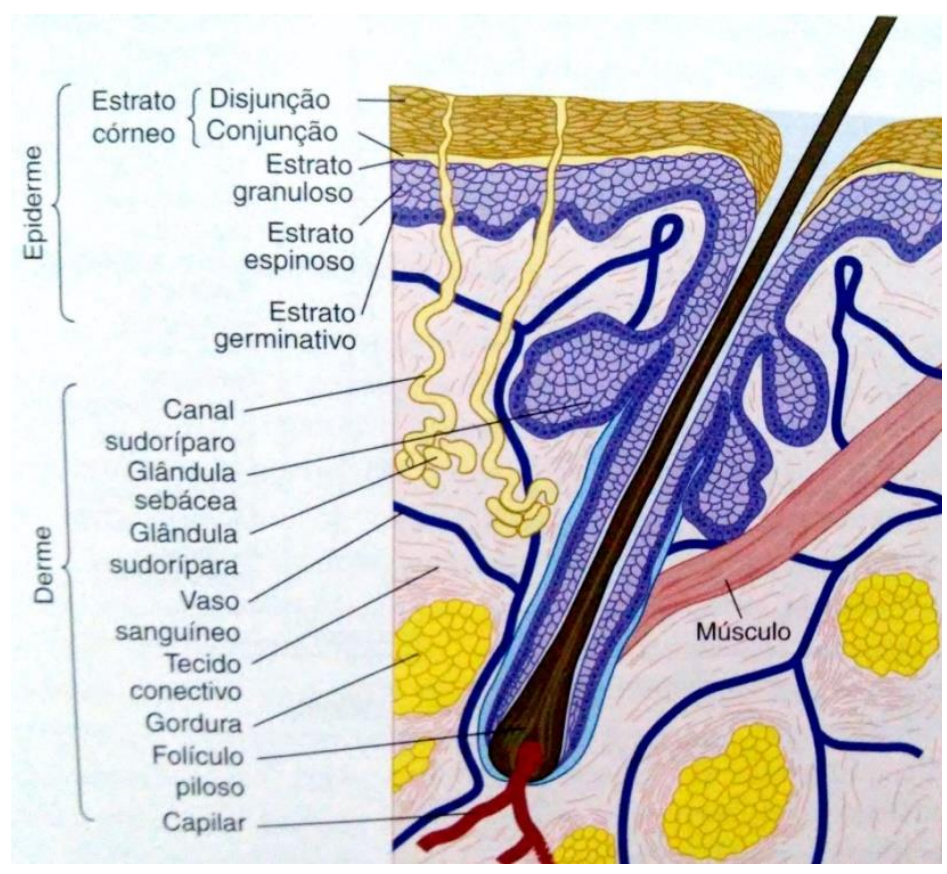

Fonte: LEHMAN-MCKEEMAN, L. D. 2012, p.63

A hipoderme é a camada mais profunda, localizada abaixo da derme e composta essencialmente de tecido adiposo. É o local onde há maior quantidade de capilares, que são responsáveis por carrear os nutrientes pelo sangue, além da presença de glândulas que são responsáveis pela saída de água e íons a fim de manter a temperatura do órgão (VENUS; WATERMAN; McNAB, 2011; JOSSET et al., 2014).

A derme é a camada intermediária entre a epiderme e a hipoderme, sendo o local onde estão vasos sanguíneos e anexos da pele. Esta camada é composta, essencialmente, por fibroblastos capazes de produzir colágeno e fibras de elastina, componentes que proporcionam a sustentação da pele (VENUS; WATERMAN; McNAB, 2011; JOSSET et al., 2014). 
A epiderme é a camada mais externa da pele, composta, essencialmente, por queratinócitos, melanócitos e células imunes. Como os queratinócitos são o objeto de estudo do presente trabalho, será dada maior ênfase a esta camada. A Figura 5 ilustra as estratificações desta camada, descritas a seguir e visualizadas no corte histológico (WHO, 2009; VENUS; WATERMAN; McNAB, 2011; JOSSET et al., 2014; YOUSEF; ALHAJJ; SHARMA, 2020; DIEGEL, 2019):

- Estrato basal (germinativo) é a interface entre a derme e a epiderme, composta de células cubóides, onde são encontrados os queratinócitos e melanócitos;

- Estrato espinhoso, é considerado o local de transição, onde as células começam a migrar para o ápice da epiderme. É composto por células poliédricas com filamentos que se estendem para as células vizinhas;

- Estrato granuloso, apresenta células em formato de diamantes e as células contém grânulos de queratohialina;

- Estrato córneo, é composto por células que perderam o núcleo e formaram escamas compostas por filamentos de queratina.

O estrato córneo é considerado a primeira barreira da pele, sua composição é dada essencialmente por 3 classes principais de lipídeos (colesterol, ácido graxo livre, ceramidas) que ficam organizadas em uma estrutura tridimensional. Esta camada é formada na última etapa de diferenciação (SMEDEN; BOUWSTRA, 2016).

A principal função do estrato córneo é a atuação com barreira física, de barreira de permeabilidade química, atuante na resposta imunológica inata, além de estar em constante renovação e possui a capacidade de se adaptar de acordo com as condições ambientais (YOUSEF; ALHAJJ; SHARMA, 2020; ABDAYEM; HAFTEK, 2018). Brohem et al. (2010) considera que o uso de modelos tridimensionais de pele/epiderme, para os mais variados estudos, é possível devido a possibilidade de gerar o estrato córneo no modelo in vitro. Além disso, incidência de alterações no estrato córneo, está ligada a ocorrência de injúrias na pele como inflamação, irritação. 
Figura 5- Diferenciação das camadas da epiderme

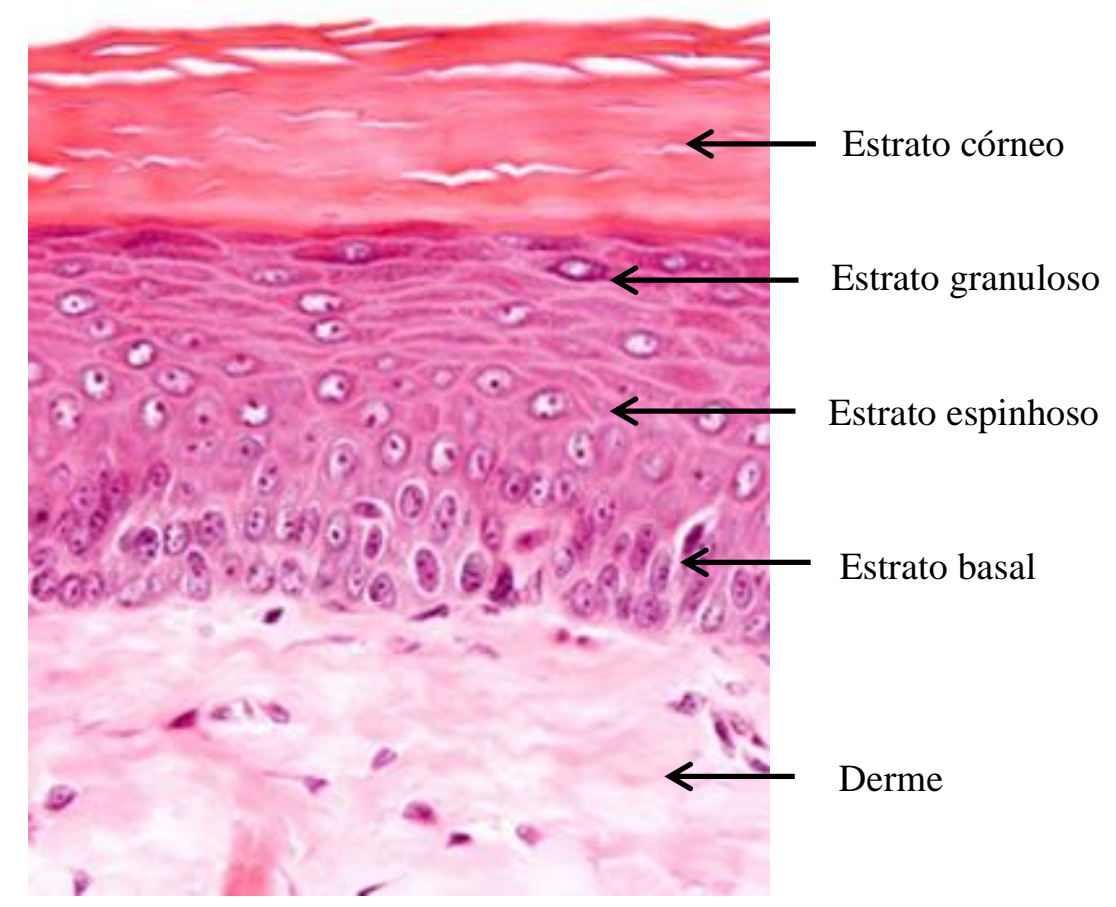

Fonte: Modificado de http://mol.icb.usp.br/index.php/2-23-tecido-epitelial-de-revestimento-2/. Acesso em: 25 Maio 2020.

O couro cabeludo embora seja parte do tecido tegumentar, apresenta algumas diferenças na anatomia como na fisiologia, ele apresenta 3 camadas principais denominadas: epiderme, derme e subcutis. As raízes dos fios assim como as glândulas se iniciam na derme, além disso há diversas inervações responsáveis por auxiliar na sensibilidade e termo regulação do couro cabeludo (RUKWIED, 2017)

A pele é um órgão multifuncional com capacidade sensorial, barreira física e imunológica. Embora, seja uma barreira muito eficiente por apresentar diversos mecanismos que impeçam a entrada de agentes patogênicos e/ou absorção de substâncias químicas, ainda existem agentes tóxicos que podem ser absorvidos por todas as camadas da pele e provocar efeitos sistêmicos (VENUS; WATERMAN; McNAB, 2011; LEHMAN-MCKEEMAN, 2013; JOSSET et al., 2014; YOUSEF; ALHAJJ; SHARMA, 2020). Desta maneira, é importante a aplicação de ensaios toxicológicos utilizando células de pele como modelo de estudo, para predizer a ocorrência de efeitos após exposição dérmica a diversas substâncias, capacidade em penetrar pela barreira natural ou provocar os efeitos no local de contato. 


\subsection{Cultura de células da pele em 3D como método alternativo à experimentação animal: aplicando o conceito dos 3 R's}

A vivissecção para estudos de fisiologia e anatomia é uma prática antiga, e os primeiros relatos vieram do médico romano Galeno em meados do século 100, no entanto, a prática foi disseminada a partir do século XIX (CARVALHO; WAIZBORT, 2010). Desde então, o uso de animais passou a ser comum tanto na medicina, como em outras áreas do conhecimento, culminando em uma imensa quantidade de animais utilizados na pesquisa e ensino. Dentro deste contexto, desde a década de 1950, Hume e Lond já discutiam sobre esta quantidade exacerbada de animais utilizados no meio científico (HUME; LOND, 1957).

Em 1959, esses conceitos foram consolidados pela divulgação do princípio dos 3R's por Russell e Burch (1959). Originados do inglês “Reduction, Replacement e Refinement”, os 3R's significam redução da quantidade, substituição de testes e refinamento dos testes visando a eliminação do sofrimento dos animais. Em 1986, foi lançada uma diretiva na União Europeia, visando à implantação da política dos 3R's na experimentação animal e outros propósitos científicos, sugerindo o desenvolvimento de novos métodos. Em 1991, foi criada a European Union Reference Laboratory for alternatives to animal testins (EURL-ECVAM), que reiterava a diretiva de 1986 (EEC, 1986; EUROPEAN COMISSION, 2013), com o propósito de desenvolver, validar novos métodos e assim, a aplicação efetiva da política dos 3R's (LOUHIMIES, 2002).

No ano de 1998, o conselho europeu expôs em uma conferência, a necessidade de proteger os animais vertebrados utilizados na pesquisa, culminando na criação de outras diretivas (EEC, 2010). Em 2005, foi criada a European Partnership for Alternatives Approaches to Animal testing (EPAA), a primeira organização que unia colaboradores do setor público e privado com o propósito de trabalhar juntos para o desenvolvimento de novos métodos mais preditivos, sem a necessidade de utilização de animais (COZIGOU et al., 2015). Ainda em 1998, foi publicada no Brasil a Lei n. 9.605, conhecida como Lei de Crimes ambientais, que em seu Capítulo V, seção I, artigo 32 diz que é crime o abuso, maus tratos, mutilação e ferimentos em animais utilizados para fins didáticos ou científicos (BRASIL, 2008).

A partir da promulgação da Lei, a comunidade científica brasileira iniciou as discussões sobre o tema e seguindo a tendência mundial neste mesmo ano, foi promulgada a Lei 
11.794/2008, mais conhecida como Lei Arouca, que regulamenta o uso de animais em pesquisa e criou o Conselho Nacional de Controle de Experimentação Animal (CONCEA) para a fiscalização do cumprimento das normas relacionadas ao uso de animais na pesquisa e ensino, podendo aplicar multas quando não há cumprimento dos requisitos estabelecidos na Lei (BRASIL, 2008; PRESGRAVE, 2008).

No ano seguinte, a União Europeia estabeleceu que cosméticos não poderiam ser comercializados caso houvesse algum componente na fórmula que tivesse sido testado em animais, já que a ECVAM juntamente com a Organisation for Economic Cooperation and Development (OECD) desde a década de 90 trabalhava continuamente para o desenvolvimento, validação, aprovação e publicação de métodos alternativos ao uso de animais (EC, 2009). A Diretiva do conselho europeu publicada em 2010, além de citar diversas considerações sobre como deve ser o manejo desses animais, propõe formas de proteção animal (EEC, 2010).

Em 2012, o Ministério da Ciência, Tecnologia e Inovação (MCTI) instituiu a Rede Nacional de Métodos Alternativos (RENAMA) para a implantação, validação e certificação de ensaios alternativos ao uso de animais, promoção da qualidade dos ensaios, avaliação da qualidade dos ensaios. Nesta mesma portaria ficou estabelecido que o processo de validação dos métodos propostos ocorreria no Centro Brasileiro de Validação de Métodos Alternativos (BraCVAM) e o monitoramento e a introdução de novas técnicas seriam de responsabilidade do CONCEA (BRASIL, 2012).

Em 2014, a Diretoria Colegiada da Agência Nacional de Vigilância Sanitária (Anvisa Dicol), deliberou a aceitação dos métodos alternativos incentivada pelo CONCEA após a publicação da resolução normativa $n^{\circ} 18$ em setembro, reconhecendo a validação de 17 métodos alternativos ao uso de animais (BRASIL, 2014). No ano de 2016 o CONCEA por meio de outra resolução normativa reconheceu mais 7 métodos alternativos (BRASIL, 2016).

Os métodos alternativos aceitos pelo CONCEA são classificados em: avaliação do potencial de irritação e corrosão da pele; avaliação do potencial de irritação e corrosão ocular; avaliação do potencial de fototoxicidade; avaliação de absorção cutânea; avaliação do potencial de sensibilização cutânea; avaliação de toxicidade aguda; avaliação de genotoxicidade, avaliação de toxicidade reprodutiva, avaliação da contaminação pirogênica em produtos injetáveis. Concomitante ao reconhecimento desses métodos, foi estabelecido um prazo de cinco anos para a substituição obrigatória de testes utilizando animais por métodos alternativos 
na pesquisa científica para o lançamento de novos cosméticos que já tenham um alternativo entre os aceitos contando o prazo desde a publicação de 2014 (BRASIL, 2014) e tal normativa entrou em vigor em setembro de 2019 (BRASIL, 2016).

Essencialmente, a avaliação dos efeitos na pele compõe a maioria dos métodos reconhecidos pelo CONCEA, pois visam, principalmente, a substituição dos ensaios de irritação e corrosão utilizando coelhos, também conhecido como teste de Draize (DRAIZE; WOODARD; HERBERT, 1944; PEDROSA et al., 2017). Esses métodos já foram validados pela OECD e descritos nos guias TG 431 e TG 439 (OECD, 2019a,b), substituindo completamente o teste de Draize.

Dentre esses métodos, as culturas celulares utilizando células de pele se destacam. A utilização de cultura celular em monocamada é um método convencional muito utilizado na pesquisa, especialmente na Toxicologia, para avaliação de efeitos induzidos após a exposição a substâncias tóxicas. No entanto, a disposição das células em uma única camada não reproduz o ambiente tecidual, tanto devido à conformação das células, quanto pela ausência da comunicação intercelular que é promovida pela coesão entre elas. Essa falha estrutural interfere nas respostas celulares e, como consequência, há a modificação do efeito quando comparado ao ambiente in vivo (POUMAY; COQUETTE, 2007).

Dentre as desvantagens dos modelos convencionais, pode-se citar também a ausência dos componentes extracelulares encontrados no tecido, como a matriz extracelular por exemplo, prejudicando não só a comunicação intercelular, mas também a diferenciação morfológica das células. Por esse motivo, o desenvolvimento de uma ferramenta de estudo com fisiologia mais complexa e que se aproxima do microambiente tecidual in vivo, melhora a capacidade de resposta dos métodos in vitro (MAZZOLENI; LORENZO; STEIMBERG, 2009; MATHES; RUFFINER; GRAF-HAUSNER, 2014).

Diversos modelos de cultura 3D foram desenvolvidos com o objetivo de mimetizar o tecido in vivo. Existem por exemplo, diversos tipos de modelos como esferoides, cultivo celular utilizando biorreatores ou cultivo com utilização de scaffolds e a matriz extracelular é escolhida de acordo com o tipo celular, características da célula escolhida e tecido a ser reproduzido (MAZZOLENI; LORENZO; STEIMBERG, 2009).

Os modelos de pele são confeccionados sob scafollds (insertos), para o crescimento e conformação adequada das camadas celulares da derme e epiderme. Neste caso, são utilizados 
fibroblastos associados a colágeno que compõem a derme e, sobre esta, são adicionados queratinócitos para a formação da camada da epiderme (Figura 6A) (POUMAY; COQUETTE, 2007; BROHEM et al, 2010; CATARINO et al., 2018).

Devido à necessidade de diferenciação celular ao longo da epiderme, é necessário que o cultivo ocorra em interface ar-líquido, uma vez que no ambiente in vivo a pele também não está submersa em fluidos. Além disso, é necessária a adição de diversos substratos, que favorecem a migração e diferenciação das células (BROHEM et al., 2010; CATARINO et al., 2018).

Figura 6- Ilustração do cultivo celular em modelo tridimensional e comparação entre a pele de roedores, pele humana e pele artificial.

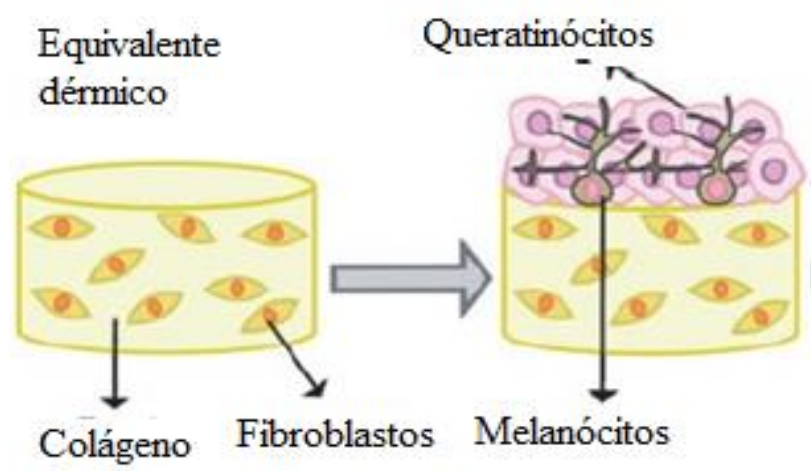

tipo I

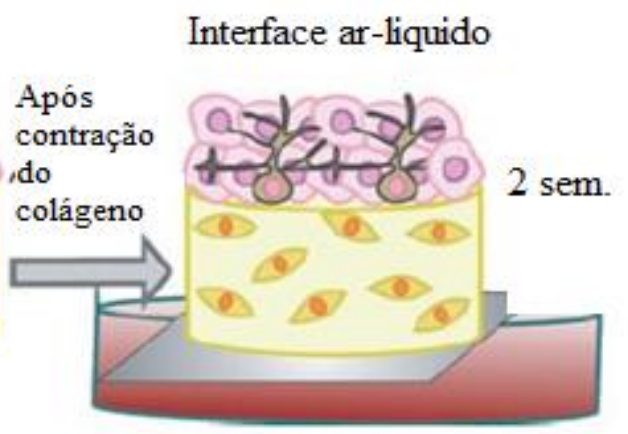

A)

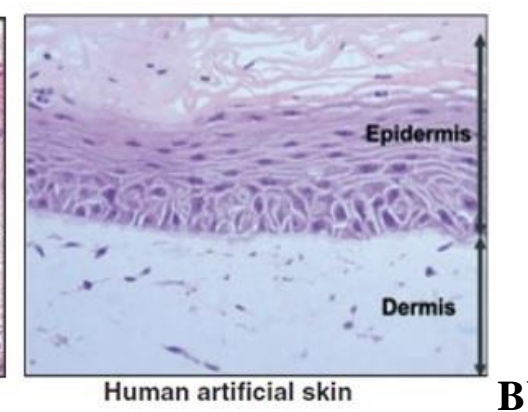

Fonte: Adaptação Brohem et al. (2010)

A) Representação do cultivo celular do modelo tridimensional de pele, demonstrando o modo de inserção das células e cultivo em interface ar-líquido. B) Comparação entre a pele de roedor, pele humana e pele artificial.

A construção da epiderme permite a formação das camadas celulares presentes no tecido in vivo, melhorando a qualidade das respostas, além de permitir a aplicação na indústria e na pesquisa. Embora esses modelos tenham limitações, Brohem et al. (2010) demonstraram que a pele artificial apresenta maior semelhança com a pele humana, quando comparada à pele de 
roedor (Figura 3B) (POUMAY; COQUETTE, 2007; BROHEM et al., 2010; PEDROSA et al., 2017).

Diversos estudos já demonstraram a eficiência dos modelos de epiderme em 3D em estudos de avalição de segurança dérmica. Jong et al. (2018) por exemplo, confirmaram que o modelo Skin Ethic ® produzido e comercializado pela L'Oreal é robusto para a detecção de atividade irritante causada por diversas substâncias químicas, listadas no protocolo da OECD TG439, após uma avaliação interlaboratorial.

No entanto, devido à dificuldade de tramitação na importação dos modelos comercialmente disponíveis, o desenvolvimento de modelos in house acabou se tornando uma necessidade (PEDROSA et al., 2017; CATARINO et al., 2018). Mesmo que recentemente a Episkin, empresa do grupo L'Oreal que comercializa modelos tridimensionais se instalou no Brasil, a tendência mundial de utilização de métodos alternativos está cada vez maior e a demanda dos modelos na América Latina provavelmente será maior do que a empresa poderá atender. Desta forma, o presente trabalho teve como um dos principais objetivos o desenvolvimento de um modelo tridimensional de epiderme, utilizando células imortalizadas, que foi utilizado para a avaliação de toxicidade dérmica induzida por corantes de cabelo.

\subsection{Testes alternativos de toxicidade dérmica}

A exposição aos cosméticos ocorre essencialmente na pele e alguns produtos podem ser absorvidos por todas as camadas desta, atingindo a circulação sanguínea, podendo induzir a efeitos sistêmicos, além dos efeitos locais. Com isso, pode-se considerar o estrato córneo presente na camada mais superficial da epiderme, a barreira física mais importante de proteção da pele (SCCS/1564/15) e o rompimento de sua integridade está relacionado a injúrias na pele.

Os efeitos tóxicos na pele podem ser classificados como agudos, subcrônicos e crônicos. Dentre os efeitos agudos, normalmente decorrentes de exposições de curto prazo, podemos destacar corrosão, irritação e sensibilização (DRAIZE; WOODARD; CALVERY, 1944; UN, 2018; DIEGEL, 2019).

Os primeiros ensaios utilizados para avaliação de efeitos locais na pele, como corrosão e irritação utilizavam pele de animais de mais de uma espécie. Dentre os animais mais utilizados, estavam os roedores, coelhos e cachorros. O ensaio de Draize ficou muito conhecido pela dor e sofrimento causado nos animais em teste, mas em meados da década de 40 , era muito 
utilizado para avaliação de efeitos na pele e nos olhos e era capaz de diferenciar entre efeito agudo, subcrônico e crônico (DRAIZE; WOODARD; CALVERY, 1944).

Desde a época, a comunidade científica buscava uma classificação adequada para os efeitos que as substâncias testadas provocavam na pele, de acordo com a intensidade do efeito. Primeiramente, a classificação era definida entre substâncias que não causavam efeitos, as corrosivas que provocavam efeitos graves de necrose e descamação desde a epiderme até a derme e, as substâncias irritantes que eram capazes de provocar edema, escaras e vermelhidão na pele e a intensidade de tais efeitos era medida por meio de scores em características prédeterminadas (DRAIZE; WOODARD; CALVERY, 1944). Atualmente, segundo o Globally Harmonised System (GHS) as substâncias corrosivas se diferem das irritantes pela gravidade do efeito que provocam após a exposição. As substâncias corrosivas são capazes de provocar um dano irreversível, diferente das substâncias irritantes, que induzem a danos que podem ser revertidos. Assim, o GHS estabeleceu 3 classificações de efeito: 1 (corrosivo), 2 (irritante) e 3 (médio irritante) sendo esta última aplicada apenas para substâncias específicas. Tais classificações foram baseadas em respostas obtidas com o uso de animais (UN, 2018).

De acordo com Diegel (2019), os principais efeitos provocados após injúrias na pele devido a ação de agentes irritantes são: reações inflamatórias na derme, espessamento do estrato córneo e, em casos mais graves, o espessamento da epiderme toda. Já a corrosão, provoca necrose superficial, podendo se espalhar para a epiderme toda, dependendo da gravidade.

Os protocolos da OECD para essas avaliações começaram a ser desenvolvidos na década de 80. Os guias n.404 e n.406 tratam de testes in vivo para avaliação de efeitos em decorrência de exposição dérmica em animais, como corrosão e sensibilização, respectivamente (OECD, 1992; OECD, 2015a). Entretanto, após o fortalecimento do princípio dos 3R's, novas formas de avaliação de risco e segurança de substâncias começaram a ser exploradas, visando a substituição do uso de animais e, quando não fosse possível, ao menos a redução no uso. Com isso o guia n. 406 foi substituído pelo 429 por melhor atender ao princípio dos 3R's, promovendo menos sofrimento aos animais utilizados nos testes de avaliação de sensibilização (OECD, 2010).

Em março de 2002, ocorreu um encontro promovido pela OECD na comunidade científica, quando foram discutidos diversos pontos importantes a respeito do desenvolvimento e validação de métodos alternativos ao uso de animais. Esse encontro originou um documento importante sobre a avaliação de risco e segurança de substâncias, descrevendo os principais requisitos que devem constar em novas metodologias para essas avaliações. A partir da 
publicação deste documento, diversos protocolos passaram a ser desenvolvidos e aplicados, sempre considerando os 3R's (OECD, 2005).

Mesmo com a ascensão dos testes in vitro, alguns testes in vivo tais como os guias 402 (toxicidade dérmica aguda), 404 (Irritação/Corrosão dérmica aguda) e 429 (Sensibilização cutânea) ainda são usados em situações que essas avaliações ainda se façam necessárias. Mas vale ressaltar que todos os testes foram modificados para atender os requisitos exigidos pela OECD para o refino, minimizando ao máximo o sofrimento físico e psicológico dos animais (OECD, 2010; OECD,2015a; OECD, 2017).

Dentre os testes in vitro atualmente recomendados para avaliação da toxicidade dérmica aguda, estão os guias da OECD 430 (corrosão da pele in vitro: método de resistência elétrica transcutânea), 435 (avaliação de barreira in vitro), 431 (avaliação de corrosão utilizando Reconstructed Human Epidermis - RHE) e 439 (avaliação de irritação utilizando RHE) (OECD, 2010; OECD, 2015b,c; OECD, 2017; OECD, 2019a,b). Além dos testes propriamente ditos, os protocolos 431 e 439 também indicam a necessidade de avaliar a proficiência de modelos desenvolvidos visando a validação empregando testes histológicos e avaliação da função como barreira, para que possam ser utilizados na avaliação da toxicidade aguda dérmica (OECD, 2019a; OECD, 2019b).

Em 2015, a OECD publicou um documento para estabelecer requisitos importantes e específicos para a validação e utilização dos protocolos 431 e 439 (OECD, 2015d; OECD, 2015e). Dentre os requisitos indispensáveis estão os métodos permitidos para a realização da determinação do sal de formazan na avaliação da viabilidade celular, o tempo de exposição necessário, princípios para a classificação da substância quanto a sua toxicidade de acordo com o efeito provocado no tecido. Além disso, cada documento apresenta uma lista de substâncias padronizadas que devem ser utilizadas na avaliação da proficiência do modelo de forma a produzir resultados fidedignos.

O teste de irritação, segundo ao protocolo 439 considera que para uma substância teste ser considerada irritante no teste in vitro, é necessário que a viabilidade seja inferior a 50\% quando comparado ao controle negativo. Já o protocolo 431, considera que uma substância teste é corrosiva quando a viabilidade for inferior a 35\% em comparação ao controle negativo. Como são avaliados alguns tempos de exposição pré-determinados, a gravidade do efeito é determinada de acordo com o período em que ocorre a queda na viabilidade (OECD, 2015d; OECD, 2019a,b). A padronização determinada pelos protocolos, são essenciais para os resultados obtidos serem confiáveis e comparáveis aos outros modelos (KANDÁROVÁ et al., 2018). 
Neste trabalho, além dos ensaios de irritação e corrosão citados no item 1.3, estudamos também a capacidade dos corantes estudados de induzir a morte celular e genotoxicidade.

\subsection{Morte celular e genotoxicidade}

As células possuem um maquinário complexo e responsável por manter as funções celulares e, quando são expostas a estressores extremos sejam eles mecânicos ou físicoquímicos, a célula pode entrar em processo de morte (GALUZZI et al., 2015). Muitas vezes a morte celular não é considerada um mecanismo prejudicial, pois alguns eventos ocorrem para manter a homeostasia do organismo (GALUZZI et al., 2015).

As células ao entrarem em processo de morte, liberam alguns marcadores. Dependendo do tipo de sinalização ou injúria que ocorre na célula o processo de morte celular percorre um caminho diferente (GALUZZI et al., 2015). Atualmente, são conhecidos diferentes processos de morte celular:

- Apoptose: ocorre por ativações bioquímicas promovidas por caspases que são responsáveis por ativar uma cascata de reações que induz a alterações morfológicas na célula como a fragmentação do DNA e destruição de organelas. Geralmente a célula que entra neste processo de morte não danifica as células vizinhas (KABAKOV; GABAI, 2018; D’ARCY, 2019);

- Piroptose: o processo de morte por essa via é bastante comparável a apoptose, no entanto nesta ocorre a ativação de interleucinas, que são mediadores relacionados às respostas inflamatórias. Além disso, essas citocinas são liberadas no meio extracelular, tornando a resposta maior, atingindo células vizinhas (D’ARCY, 2019);

- Autofagia: processo de morte que ocorre quando a célula detecta a restrição energética, que pode estar relacionada a fatores extrínsecos ou não. A partir disso, a própria célula começa a promover uma degradação interna para a obtenção de energia, através da reciclagem das organelas em excesso, sendo um evento que promove diminuição da capacidade metabólica da célula. Porém, quando a privação enérgica é intensa, o processo pode evoluir para morte (D’ARCY, 2019); 
- Necrose: processo de morte celular que ocorre devido a uma injúria grave que faz com que a célula não consiga se recuperar. Geralmente, o efeito atinge células vizinhas e o processo de morte acontece em mais de uma célula (KABAKOV; GABAI, 2018; D’ARCY, 2019).

A avaliação do mecanismo de morte celular por métodos variados é importante para a avaliação da ocorrência da ativação de um ou mais processos celulares. Neste trabalho, forma utilizados três diferentes métodos de avaliação de viabilidade celular, como será apresentado no item 3 deste documento.

A molécula de DNA como é conhecida hoje, foi descrita pela primeira vez por Watson e Crick na década de 50. O DNA está presente nas células e carrega as informações essenciais de um indivíduo, garantindo a estabilidade e integridade genômica, para que as informações sejam passadas corretamente para as novas gerações celulares após a divisão. Quando ocorre um dano à molécula de DNA, ou genotoxicidade, que o sistema de reparo celular não é capaz de corrigir, esse dano pode ser passado para gerações posteriores, evento conhecido como mutação (RADHIKA; JYOTHI, 2019; WATSON; CRICK, 1953; CLANCY, 2008; PRAY, 2008).

Os testes de avaliação de genotoxicidade e mutagenicidade são utilizados para a identificação do potencial das substâncias em provocar danos no DNA, além disso possuem um papel na regulamentação de produtos. Pelo fato de existirem diversos tipos de dano que podem ocorrer, existem diversos testes disponíveis para a determinação dos mecanismos de dano (DOMINGUEZ; SALES, 2007; RADHIKA; JYOTHI, 2019). Neste trabalho, foi utilizado o ensaio do Cometa in vitro. O princípio do teste consiste na avaliação de quebras de DNA de cadeias duplas ou simples e sítios álcali-labeis em núcleos de células após a aplicação de uma corrente eletroforética capaz de separar por tamanho e peso os fragmentos de DNA (TICE et al., 2000; OECD, 2016). 
CONCLUSÕES 


\section{CONCLUSÕES}

Com os dados obtidos neste trabalho podemos concluir:

1- Quanto a validade do modelo desenvolvido:

- O modelo de pele humana equivalente (HaCaT-EHE) foi desenvolvido com sucesso e, apresenta características histológicas, capacidade de diferenciação celular e função de barreira semelhantes a outros modelos validados, com a vantagem de não utilizar células primárias e sim células imortalizadas;

- O método de validação analítica demonstrou reprodutibilidade, exatidão, linearidade nas concentrações de trabalho, além de não demonstrar interferência da matriz;

- Adicionalmente, o HaCaT-EHE pode ser utilizado para estudos preliminares de avaliação da segurança de produtos cosméticos, devido a sua capacidade de distinguir efeitos irritantes e corrosivos, com bom valor preditivo de acordo com a recomendação da OECD.

2- Quanto a aplicação do modelo para estudo de toxicidade de corantes de cabelo:

- O corante Basic Blue 99 tem a citotoxicidade como principal mecanismo de toxicidade dérmica, revelada pela indução de apoptose, irritação e corrosão de células da epiderme. Já o corante Basic Red 51, tem como principal mecanismo de toxicidade, a genotoxicidade.

Desta forma, como os efeitos induzidos em modelo que mimetizam a resposta humana foram detectados em concentrações menores do que as encontradas em formulações comerciais, a utilização destes corantes em tinturas capilares deve ser revista. 
REFERÊNCIAS 


\section{REFERÊNCIAS}

ABDAYEN, R.; HAFTEK, M. The epidermal barrier. Annales of Dermatologie et de Venereologie, France, v. 145, n.4, p. 293-301, 2018.

ABO, T.; YUKI, T.; XU, R.; ARAKI, D.; TAKAHASHI, Y.; SAKAGUCHI, H.; ITAGAKI, $H$. Expansion of the applicability domain for highly volatile substances on the short time exposure test method and the predictive performance in assessing eye irritation potential. The journal of Toxicological Sciences, Toquio, v. 43, n. 7, p. 407-422, 2018.

AGÊNCIA BRASIL. Veja as medidas que cada estado está adotando para a covid-19. 2020. Disponível em: < https://agenciabrasil.ebc.com.br/saude/noticia/2020-03/veja-medidas-quecada-estado-esta-adotando-para-combater-covid-19 >. Acesso em 26 Maio 2020.

ALARIFI, S.; ALI, D.; ALAKHTANI, S.; AL SUHAIBANI, E. S.; AL-QAHTANI, A. A. Reative oxygen species-mediated DNA damage and apoptosis in human skin epidermal cells after exposure to nickel nanoparticles. Biological Trace Element Research, Totowa, v. 157, p. 84-93, 2014.

ALÉPÉE, N.; TORNIER, C.; ROBERT, C.; AMSELLEM, C.; ROUX, M-H.; DOUCET, O.; PACHOT, J.; MÉLONI, M.; BRUGEROLLE, FRAISSINETTE, A. B. A catch- p validation study on reconstructed human epidermis (SkinEthic ${ }^{\mathrm{TM}}$ RHE) for full replacement od Draize skin irritation test. Toxicology in Vitro, Oxford, v. 24, p.257-266, 2010.

ALÉPÉE, N; ROBERT, C.; TORNIER, C.; COTOVIO, J. The usefulness of the validated SkinEthicTM RHE test method to identify skin corrosive UN GHS subcategories. Toxicology in Vitro, Oxford, v. 28, p. 616-625, 2014.

ALÉPÉE, N.; BARROSO, J.; SMEDT, A. D.; WEVER, B. D.; HIBATALLAH, J.; KLARIC, M.; MEWES, K. R.; MILLET, M.; PFANNENBECKER, U.; TAILHARDAT, M.; TEMPLIER, M.; MCNAMEE, P. Use of HPLC/UPLC'spectrophotometry for detection of formazan in in vitro reconstruction human tissue (RhT)- based test methods employing the MTT-reduction assay to expand their applicability to strongly coloured test chemicals. Toxicology in vitro, Oxford, v.29, p.741-761, 2015.

ALÉPÉE, N.; GRANDIDIER, M-H.; COTOVIO, J. Usefulness of the EpiskinTM reconstructed human epidermis model within integrated approaches on testing and assessment (IATA) for skin corrosion and irritation. Toxicology in Vitro, Oxford, v. 54, p. 147-167, 2019.

ALERICO, G. C.; BECKENKAMP, A.; VIGNOLI-SILVA, M.; BUFFON, A.; POSER, G.L. Proliferative effect of plants used for wound healing in Rio Grande do Sul state, Brazil. Journal of Ethnopharmacology, Clare, v.176, p.305-310, 2015.

ALIBARDI, L. Cornification in reptilian epidermis occurs through the deposition of keratinassociated beta proteins (beta-keratins) onto a scaffold of intermediate filament keratins. Journal of Morphology, Hoboken, v. 274, p. 175-193, 2013.

AMERICAN CANCER SOCIETY. Hair Dyes. 2019. Disponível em: < https://www.cancer.org/cancer/cancer-causes/hair-dyes.html > Acesso em: 02 Maio 2020. 
em: < https://abihpec.org.br/publicacao/panorama-do-setor-2019-2/ > Acesso em: 25 Maio 2020.

ASSOCIAÇÃO BRASILEIRA DA INDÚSTRIA DE HIGIENE PESSOAL, PERFUMARIA E COSMÉTICOS. Venda de produtos de higiene e beleza cai até 15\% . 2020a. Disponível em: < https://abihpec.org.br/venda-de-produto-de-higiene-e-beleza-cai-ate-15/ >. Acesso em 26 Maio 2020.

ASSOCIAÇÃO BRASILEIRA DA INDÚSTRIA DE HIGIENE PESSOAL, PERFUMARIA E COSMÉTICOS. Venda de itens de higiene cresce enquanto de outros segmentos caem. 2020b. Disponível em: < https://abihpec.org.br/venda-de-itens-de-higiene-cresce-enquanto-deoutros-segmentos-caem/ > . Acesso em 26 Maio 2020.

BANKS-SCHLEGEL, S. GREEN, H. Involucrin synthesis and tissue assembly by keratinocytes in natural and cultured human epithelia. Journal of Cell Biology, New York, v. 90, p. 732-737, 1981.

BOELSMA, E.; VERHOEVEN, M. C. H.; PONEC, M. Reconstruction of a human skin equivalent using a spontaneously transformed keratinocyte cell line (HaCaT). Journal of Investigative Dermatology, New York, v.112, p.489-498, 1999.

BRASIL. Agencia nacional de vigilância sanitária. RDC no 19 de 10/04/2013. 2013. Disponível em:

http://portal.anvisa.gov.br/legislacao/?inheritRedirect=true\#/visualizar/356500 >. Acesso em 25 Abr. 2020.

BRASIL. Agencia nacional de vigilância sanitária. Anvisa aceita 17 métodos alternativos validados em substituição ao uso de animais. 2014. Disponível em: < http://portal.anvisa.gov.br/noticias/-/asset_publisher/FXrpx9qY7FbU/content/anvisa-aceita17-metodos-alternativos-validados-em-substituicao-ao-uso-deanimais/219201/pop_up?inheritRedirect=false >. Acesso em: 25 Maio 2020.

BRASIL. Câmara dos Deputados. Projetos de leis e outras proposições. 2013. Disponível em: < http://www.camara.gov.br/proposicoesWeb/fichadetramitacao?idProposicao=597587 >. Acesso em: 25 Maio 2020.

BRASIL. Instituto brasileiro do meio ambiente e dos recursos naturais renováveis. Lei dos crimes ambientais: Lei $n^{\circ} \mathbf{9 . 6 0 5}$, de 12 de fevereiro de 1998 e decreto $n^{\circ} 6.514$, de 22 de julho de 2008. 2014. Disponível em: http://www.ibama.gov.br/sophia/cnia/livros/ALeiCrimesAmbientais.pdf > Acesso em 20 Maio 2020.

BRASIL. Lei 11.794, de 8 de outubro de 2008. Subchefia para Assuntos Jurídicos. BrasíliaDF. Disponível em: < http://www.planalto.gov.br/ccivil_03/_ato20072010/2008/lei/111794.htm > Acesso em 25 Maio 2020.

BRASIL. Ministério da Saúde. Agência Nacional de Vigilância Sanitária. Resolução RDC n 44, de 9 de agosto de 2012. 2012. Disponível em: < https://bvsms.saude.gov.br/bvs/saudelegis/anvisa/2012/rdc0044_09_08_2012.html\#: :text=A prova\%20o\%20Regulamento\%20T\%C3\%A9cnico\%20Mercosul,perfumes\%22\%20e\%20d\% C3\%A1\%20outras\%20provid\%C3\%AAncias. >. Acesso em 25 Set. 2020. 
BRASIL. Ministério de Estado da Ciência, Tecnologia e Inovação. Portaria no 491 de 3 de julho de 2012. 2012. Disponível em: < https://www.jusbrasil.com.br/diarios/38460811/dousecao-1-05-07-2012-pg-19>. Acesso em: 25 Set 2020.

BRASIL. Ministério da Ciência, Tecnologia, Inovação e Comunicações. Concea reconhece 17 métodos alternativos ao uso de animais. 2014. Disponível em: < https://www.mctic.gov.br/mctic/opencms/legislacao/outros_atos/resolucoes/migracao/Resoluc ao_Normativa_CONCEA_n_18_de_24092014.html >. Acesso em: 25 Maio 2020.

BRASIL. Diário Oficial da União. Conselho Nacional de Controle de Experimentação Animal. Resolução normativa $\mathbf{n}^{\mathbf{0}} \mathbf{3 1}$, de 18 de agosto de 2016. 2016. Disponível em: < https://www.jusbrasil.com.br/diarios/123227518/dou-secao-1-19-08-2016-pg-4 >. Acesso em: 25 Set. 2020.

BROECKE, K. V.; BRUZE, M.; PERSSON, L.; DEROO, H.; GOOSSENS, A. Contact urticarial syndrome caused by direct hair dyes in a hairdresser. Contact Dermatitis, Malden, v. 71, p. 108-128, 2014.

BROHEM, C. A.; CARDEAL, L. B. da S.; TIAGO, M.; SOENGAS, M. S.; BARROS, S. B. de M.; MARIA-ENGLER, S. S. Artificial skin in perspective: concepts and applications. Pigment Cell \& Melanoma Research, Malden, v.24, p.35-50, 2010.

BUFFOLI, B.; RINALDI, F.; LABANCA, M.; SORBELLINI, E.; TRINK, A.; GUANZIROLI, E.; REZZANI, R.; RODELLA, L.F. The human hair: from anatomy to physiology. International Journal of Dermatology, Malden, v.53, n.3, p.331-341, 2014.

CARTNER, T.; BRAND, N.; TIAN, K.; SAUD, A.; CARR, T.; STAPLETON, P.; LANE, M. E.; RAWLINGS, A. V. Effect of different alcohols on stratum corneum kallikrein 5 and phospholipase A2 together with epidermal keratinocytes and skin irritation. Cosmetic Science, v. 39, p. 188-196, 2017.

CARVALHO, A. L. L.; WAIZBORT, R. A dor além dos confins do homem: aproximações preliminares ao debate entre francês Power Cobbe e os darwinistas a respeito da vivissecção na Inglaterra vitoriana (1863-1904). História, Ciência, Saúde, Rio de Janeiro, v. 17, n. 3, p. 577 $605,2010$.

CATARINO, C. M.; PEDROSA, T. N.; PENNCCHI, P. C.; ASSIS, S. R.; GIMENES, F.; CONSOLARO, M. E. L.; BARROS, S. B. M.; MARIA-ENGLER, S. S. Skin corrosion test: a comparison between reconstructed human epidermis and full thickness skin models. European Journal of Pharmaceutics and Biopharmaceutics, Amsterdam, v. 125, p. 51-57, 2018.

CHEQUER, F. M. D.; ANGELI, J. P. F.; FERRAZ, E. R. A.; TSUBOY, M. S.; MARCARINI, J. C.; MANTOVANI, M. S.; OLIVEIRA, D. P. The azo dyes disperse red 1 and disperse Orange 1 increase the micronuclei frequencies in human lymphocytes and in HepG2 cells. Mutation Research/ Genetic Toxicology and Environmental Mutagenesis, Amsterdam, v. 676, p. 8386, 2009.

CLANCY, S. DNA damage \& repair: mechanisms for maintaining DNA integrity. Nature Education, v. 1, n. 1, p. 103, 2008. Disponível em: < https://www.nature.com/scitable/topicpage/dna-damage-repair-mechanisms-for-maintainingdna-344/ > . Acesso em 27 Maio 2020. 
COLLINS, A. R. The comet assay for DNA damage and repair. Molecular Biotechnology, Totowa, v. 26, p. 249- 261, 2004.

COLOMBO, I.; SANGIOVANNI, E.; MAGGIO, R.; MATTOZZI, C.; ZAVA, S.; CORBETT, Y.; FUMAGALLI. M.; CARLINO, C.; CORSETTO, P. A.; SCACCABAROZZI, D.; CALVIERI, S.; GISMONDI, A.; TARAMELLI, D.; DELL'AGLI, M. HaCaT cells as a reliable in vitro differentiation model to dissect the inflammatory/repair response of human keratinocytes. Mediators of inflammation, London, p. 1-12, 2017.

COSMETIC INGREDIENT REVIEW EXPERT PANEL. Final report on the safety assessment of basic blue 99. International Journal of Toxicology, Thousand Oaks, v.26, n.2, p.51-63, 2007.

COSMETICS INFO. A history of cosmetics from ancient times. 2016. Disponível em: < http://www.cosmeticsinfo.org/Ancient-history-cosmetics > Acesso em: 21 Maio 2020.

COZIGOU, G.; CROZIER, J.; HENDRIKSEN, C.; MANOU, I.; RAMIREZ-HERNANDEZ, T.; WEISSENHORN, R. The european partnership for alternative approaches to animal testing (EPAA): promoting alternative methods in Europe and beyond. Journal of the American Association for Laboratory Animal Science, Memphis, v. 54, n. 2, p.209-213, 2015.

D'ARCY, M. S. Cell death: a review of the major forms of apoptosis, necrosis and autophagy. Cell Biology Inernational, Roboken , v. 43, p.582-592, 2019.

DHIMAN, H. K.; RAY, A. R.; PANDA, A. K. Three-dimensional chitosan scaffold based MCF-7 cell culture for the determination of the cytoxicity of tamoxifen. Biomaterials, Oxford, v.26, p.979-986, 2005.

DIEGEL, K. L. Pathology of the intergumentary system. In: STEINBACH, T. J.; PATRICK, D. J.; COSENZA, M. E. Toxicology pathology for non-pathologists. 2019. Totowa: Human Press p. 483-535.

DOMINGUEZ, M. H.; SALES, D. Safety evaluation. In: SALVADOR, A.; CHISVERT, A. Analysis of cosmetic products. 2007. Elsevier Science ed. p. 423-461.

DRAELOS, Z.D.; Hair care: an illustrated dermatologic handbook. 2004. London: Taylor \& Francis ed, 263p.

DRAIZE, H.; WOODARD, G.; CALVERY, H. O. Methods for the study of irritation and toxicity of substances applied topically to the skin and mucous membranes. Journal of Pharmacology and Experimental Therapeutics, Bethesda, p.377-390, 1944.

EC/2009. Official Journal of the European Union. Regulation 1223/2009/EC of the European parliament and of the council of 30 November 2009. 2009. Disponível em: < http://eurlex.europa.eu/legal-content/EN/TXT/PDF/?uri=CELEX:32009R1223\&from=EN > Acesso em: 25 Maio 2020.

EEC/1986. Official Journal of the European Union. Council Directive 86/609/EEC of 24 November 1986. 1986. Disponível em: < http://eur-lex.europa.eu/legalcontent/EN/TXT/PDF/?uri=CELEX:31986L0609\&from=EN > Acesso em: 25 Maio 2020. 
EEC/2010. Official Journal of the European Union. Council Directive 2010/63/EU of the European parliament and the council of 22 September 2010. 2010. Disponível em: < http://eur-lex.europa.eu/legal-content/EN/TXT/PDF/?uri=CELEX:32010L0063\&from=EN > Acesso em 25 Maio 2020.

ESKES, C.; COLE, T.; HOFFMANN, S.; WORTH, A.; COCKSHOTT, A.; GERNER, I.; ZUANG, V. The ECVAM international validation study in vitro tests for acute skin irritation: selection of test chemicals. ATLA- Alternative to Laboratory Animals, England, v. 35, p. 603-619, 2007.

EUROPEAN COMMISSION. Communication from the commission to the European parliament and the council. On the animal testing and marketing ban and on the state of play in relation to alternative methods in the field of cosmetics. 2013. Disponível em: < http://eur-lex.europa.eu/legal-content/EN/TXT/PDF/?uri=CELEX:52013DC0135\&from=EN > Acesso em: 25 Maio 2020.

EUROPEAN UNION REFERENCE LABORATORY FOR ALTERNATIVES TO ANIMAL TESTING. SkinEthic ${ }^{\mathrm{TM}}$ skin irritation test, protocol n⿳0135. 2017. Disponível em: < https://ecvam-dbalm.jrc.ec.europa.eu/methods-and-protocols/search/135 > Acesso em: 25 Maio 2020.

FENTEN, J. H.; ARCHER, G. E. B.; BALLS, M.; BOTHAM, P. A.; CURREN, R. D.; EARL, L. K.; ESDAILE, D. J.; HOLZHÜTTER, H. G.; LIEBSCH, M. The ECVAM international validation study on in vitro tests for skin corrosivity. 2 . Results and evaluation by the management team. Toxicology in Vitro, Oxford, v. 12, p. 483-524, 1998.

FERRAZ, E. R. A.; GRANDO, M. D.; OLIVEIRA, D. P. The azo dye disperse Orange 1 induces DNA damage and cytotoxic effects but does not ecotoxic effects in Daphnia similis and Vibrio fischeri. Journal of Hazardous Materials, Netherlands, v. 192, p. 628-633, 2011.

FERRAZ, E. R. A.; LI, Z.; BOUBRIAK, O.; OLIVEIRA, D. P. Hepatotoxicity assessment of the azo dyes disperse Orange 1(DO1), disperse red 1 (DR1) and disperse red 13 (DR13) in HepG2 cells. Journal of Toxicology and Environmental Health, part A, Philadelphia, v.75, p.991-999, 2012.

FLAMAND, N.; MARROT, L.; BELAID, J. P.; BOUROUF, L.; DOURILLE, E.; FELTES, M.; MEUNIER, J. R. Dvelopment of genotoxicity test procedures with Episkin, a reconstructed human skin model: towards new tools forin vitro risk assessment of dermally applied compounds? Mutation Research/ Genetic Toxicology and Environmental Mutagenesis, Amsterdam, v. 606, n.1-2, p.39-51, 2006.

FOOD AND DRUG ADMINISTRATION. Is it a cosmetic, a drug, or both? (or is it soap?). 2018a. Disponível em: < https://www.fda.gov/Cosmetics/GuidanceRegulation/LawsRegulations/ucm074201.htm > Acesso em 20 Maio 2020.

FOOD AND DRUG ADMINISTRATION. Bioanalytical method validation. 2018b. Disponível em: < https://www.fda.gov/downloads/drugs/guidances/ucm070107.Pdf >. Acesso em: 25 Maio 2020.

FONTOURA, J. C.; VIEZZER, C.; SANTOS, F. G.; LIGABUE, R. A.; WEINLICH, R.; PUGA, R. D.; ANTONOW, D.; SEVERINO, P.; BONORINO, C. Comparison of 2D and 3D 
cell culture models for cell growth, gene expression and drug resistance. Materials Science \& Engineering C, Amsterdam, v.107, p.110264, 2020.

FRANCHI, L. P.; MANSHIAN, B. B.; SOUZA, T. A. J.; SOENEN, S. J.; MATSUBARA, E. Y.; ROSOLEN, M.; TAKAHASHI, C. S. Cyto- and genotoxic effects of metallic nanoparticles in untransformed human fibroblast. Toxicology in vitro, Oxford, v. 29, n. 7, p.1319-1331, 2015.

FRANCO, J. H.; SILVA, B.F.; ZANONI, M.V.B. Using ionic liquid combined with HPLCDAD to analyze semi-permanent hair dyes in commercial formulations. Analytical Methods, Cambridge, v.7, p.1115-1122, 2015.

GALUZZI, L.; BRAVO-SAN PEDRO, J.M.; VITALE, I.; AARONSON, S. A.; ABRAMS, J. M.; ADAM, D.; ALNEMRI, E. S.; ALTUCCI, L.; ANDREWS, D.; ANNICCHIARICOPETRUZZELLI, M.; BAEHRECKE, E. H.; BAZAN, N. G.; BERTRAND, M. J.; BIANCHI, K.; BLAGOSKLONNY, M. V.; BLOMGREN, K.; BORNER, C.; BREDESEN, D. E.; BRENNER, C.; CAMPANELLA, M.; CANDI, E.; CECCONI, F.; CHAN, F. K.; CHANDEL, N. S.; CHENG, E. H.; CHIPUK, J. E.; CIDLOWSKI, J. A.; CIECHANOVER, A.; DAWSON, T. M.; DAWSON, V. L.; DE LAURENZI, V.; DE MARIA, R.; DEBATIN, K-M; DI DANIELE, N.; DIXIT, V. M.; DYNLACHT, B. D.; EL-DEIRY, W. S.; FIMIA, G. M.; FLAVELL, R. A.; FULDA, S.; GARRIDO, C.; GOUGEON, M-L, GREEN, D. R.; GRONEMEYER, H.; HAJNOCZKY, G.; HARDWICK, J. M.; HENGARTNER, M. O.; ICHIJO, H.; JOSEPH, B.; JOST, P. J.;KAUFMANN, T.; KEPP, O.; KLIONSKY, D. J.; KNIGHT, R. A.; KUMAR, S.; LEMASTERS, J. J.; LEVINE, B.; LINKEMANN, A.; LIPTON, S. A.; LOCKSHIN, R. A.; LÓPEZ-OTIN, C.; LUGLI, E.; MADEO, F.; MALOMI, W.; MARINE, J-C, MARTIN, S. J.; MARTINOU, J-C, MEDEMA, J. P.; MEIER, P.; MELINO, S.; MIZUSHIMA, N.; MOLL, U.; MUÑOZ-PINEDO, C.; NUÑES, G.; OBERST, A.; PANARETAKIS, T.; PENNINGER, J. M.; PETER, M. E.; PIACENTINI, M.; PINTON, P.; PREHN, J. H.; PUTHALAKATH, H.; RABINOVICH, G. A.; RAVICHANDRAN, K. S.; RIZZUTO, R.; RODRIGUES, C. M.; RUBINSZTEIN, D. C.; RUDEL, T.; SHI, Y.; SIMON, H-U.; STOCKWELL, B. R.; SZABADKAI, G.; TAIT, S. W.; TANG, H. L.; TAVERNARAKIS, N.; TSUJIMOTO, Y.; VANDEN BERGHE, T.; VANDENABEELE, P.; VILLUNGER, A.; WAGNER, E. F.; WALCZAK, H.; WHITE, E.; WOOD, W. G.; YUAN, J.; ZAKERI, Z.; ZHIVOTOVSKY, B.; MELINO, G.; KROEMER, G. Essential versus acessory aspects of cell death: recommendations of the NCCD 2015. Cell Death and Differentiation, London, v.22, p. 58-73, 2015.

GERA, R.; MOKBEL, R.; IGOR, I.; MOKBEL, K. Does the use of hair dyes increase the risk of developing breast câncer? A meta-analysis and review of the literature. Anticancer Research, Athens, v. 38, n.2, p. 707-716, 2018.

GUERRA-TAPIA, A.; GONZALEZ-GUERRA, E. Hair cosmetics: dyes. ACTAS DermoSifiliográficas, Spain, v. 105, p.833-839, 2014.

HAO, Y.; BAI, X.; LIU, X.; KANG, S.; ZHANG, X.; LIU, C.; LI, Z. Downregulation of surviving by adenovirus-mediated shRNA promotes apoptosis in skin cancer cells. Oncotargets and Therapy, England, v. 12, p.2921-2930, 2019.

HINGORANI, R.; DENG, J.; ELIA, J.; McINTYRE, C.; MITTAR, D. Detection of apoptosis using the BD annexin V FITC assay on the BD FACSVerse TM system, 2011. Disponível em: 
https://www.bdbiosciences.com/documents/BD_FACSVerse_Apoptosis_Detection_AppNote. pdf >. Acesso em: 25 Maio 2020.

HIRSCH, C.; SCHILDKNECHT, S. In vitro research reproducibility: keeping up high standards. Frontiers in Pharmacology, Switzerland, v.10, p. 1-9, 2019.

HOFFMAN, R. M. Three-dimensional histoculture: origins and applications in cancer research. Cancer Cell, Cambridge, v.3, p.86-92, 1991.

HUME, C.W.; LOND, M. C. B. The strategy and tatics of experimentation. The Lancet. p. 1049-1052, 1957. Disponível em: < https://www.cabdirect.org/cabdirect/abstract/19592703563 >. Acesso em 21 Maio 2020.

HWANG, J-H.; JEONG, H.; HUR, S.; NAM, K. T.; LIM, K-M. Employment of cytology for in vitro skin irritation test using a reconstructed human epidermis model, keraskim. Toxicology in Vitro, Oxford, v.69, 104962, 2020.

IDRIS, A.; ZULKIPLI, I. N.; ZULHILMI, N. R.; LEE, H. F.; RAJABALAYA, R.; CHEE, L. Y.; MAJID, M.; DAVID, S. R. Melastoma malabathricum ethyl acetate fraction induces secondary necrosis in human breast and lung cancer cell lines. Pharmacognosy Magazine, Mumbai, v. 13, p. 688-692, 2017.

INSTITUTO DE CIÊNCIAS BIOMÉDICAS. Epitélio estratificado pavimentoso corneificado. 2019. Disponível em: < http://mol.icb.usp.br/index.php/2-23-tecido-epitelial-derevestimento-2/ > Acesso em: 25 Maio 2020.

INSTITUTO NACIONAL DE METROLOGIA. Tinturas para cabelo. 2006. Disponível em: $<$ http://www.inmetro.gov.br/consumidor/produtos/tintura_cabelo.asp > Acesso em: 25 Maio 2020.

INTERNATIONAL AGENCY RESEARCH on CANCER. Occupational exposures of hairdressers and barbers and personal use of hair colourants. v.99, 2010. Disponível em: < http://monographs.iarc.fr/ENG/Monographs/vo199/mono99.pdf > Acesso em: 25 Maio 2020.

JIANN, B-P. Does hair dye use really increase the risk of prostate cancer? BMC Cancer, London, v. 17, n. 1, p. 724-728, 2017.

JONG, W. H.; HOFFMANN, S.; LEE, M.; KANDÁROVÁ, H.; PELLEVOISIN, C.; HAISHIMA, Y.; ROLLINS, B.; ZDAWZCYK, A.; WILLOUGHBY, J.; BACHELOR, M.; SCHATZ, T.; SKOOG, S.; PARKER, S.; SAWYER, A.; PESCIO, P.; FANT, K.; KIM, K.; KWON, J. S.; GEHRKER, H.; HOFMAN-HÜTHER, H.; MELONI, M.; JULIUS, C.; BRIOTET, D.; LETASIOVA, S.; KATO, R.; MIYAJIMA, A.; FONTEYNE, L.; VIDEAU, C.; TORNIER, C.; TURLEY, A.; CHRISTIANO, N.; ROLLINS, T.; COLEMAN, K. P. Round robin study to evaluate the reconstructed human epidermis (RHE) model as an in vitro skin irritation test for detection of irritant activity in medical device extracts. Toxicology in Vitro, Oxford, Disponível em: < https://doi.org/10.1016/j.tiv.2018.01.001 > Acesso em 30 Jan. 2018.

JOSSET, P.; BUENO, V. SANT'ANA, O. A. Histology and immunology of the skin. In: MAIBACH, H. I.; HALL, A. H. Chemical skin injury. 2014. Berlin: Springer, p. 21-42. Disponível em: < https://link.springer.com/book/10.1007\%2F978-3-642-39779-0 > Acesso em: 29 Abr. 2020. 
JUNG, K.-M.; LEE, S-H.; JANG, W-H.; JUNG, H-S.; HEO, Y.; PARK, Y-H.; BAE, S.; LIM, K-M.; SEOK, S.H. KeraSkin TM_VM: a novel reconstructed human epidermis model for skin irritation tests. Toxicology in Vitro, Oxford, v. 28, p. 742-750, 2014.

KABAKOV, A. E.; GABAI, V. L. Cell death and survival assays. In: CALDERWOOD, S.; PRINCE, T. Chaperones. Methods in molecular biology, v. 1709 p. 107-127, 2018. Human Press, New York-NY.

KANDÁROVÁ, H.; LIEBSCH, M.; SPIELMANN, H.; GENSCHOW, E.; SCHMIDT, E.; TRAUE, D.; GUEST, R.; WHITTINGHAM, A.; WARREN, N.; GAMER, A. O.; REMMELE, M.; KAUFMANN, T.; WITTMER, E.; WEVER, B.; ROSDY, M. Assessment of the human epidermis model SkinEthic RHE for in vitro corrosion testing of chemicals according to new OECD TG 431. Toxicology in Vitro, Oxford, v. 20, p.547-559, 2006.

KANDÁROVÁ, H.; WILlOUGHBY, J. A.; JONG, W. H.; LETASIOVA, S.; MILASOVA, T.; BACHELOR, M. A.; BREYFOGLE, B.; HANDA, Y.; FONTEYNE, L.; COLEMAN, K. P. Pre-validation of an in vitro skin irritation test for medical devices using the reconstructed human tissue model EpiDerm ${ }^{\text {TM }}$. Toxicology in Vitro, Oxford, v. 50, p.407-417, 2018.

KIM, K-H; KABIR, E.; JAHAN, S. A. The use of personal hair dye and its implications for human health. Environment International, Oxford, v. 89-90, p. 222-227, 2016.

KUMARAVEL, T. S.; VILHAR, B.; FAUX, S. P.; JHA, A. N. Comet assay measurements: a perspective. Cell Biology and Toxicology, Netherlands, v.25, p.53-64, 2009.

KUO, Y.H.; CHIANG, H-L.; WU, P-Y.; CHANG, Q-X.; WEN, K-C.; LIN, C-Y.; CHIANG, $\mathrm{H}-\mathrm{M}$. Protection against ultraviolet A-induced skin apoptosis and carcinogenesis through the oxidative stress reduction effects of $\mathrm{N}$-(4- bromophenetyl) caffeamide, a propolis derivative. Antioxidants, Switzerland, v.9, n.4, p.1-17, 2020.

KYRYLKOVA, K.; KYRYACHENKO, S.; LEID, M.; KIOUSSI, C. Detection of apoptosis by TUNEL assay. 2012. Disponível em: < https://link.springer.com/protocol/10.1007\%2F9781-61779-860-3_5 >. Acesso em 01 Jun 2020.

LEHMAN-MCKEEMAN, L. D. Absorção, distribuição e excreção de toxicantes. In: Casarett \& Doull's: Fundamentos de toxicologia. Porto Alegre: AMGH, p.63, 2012.

LEHMAN-MCKEEMAN, L. D. Absorption, distribution and excretion of toxicants. In: KLAASSEN; C. D. Casarett \&Doull's toxicology: the basic science of poisons. Mc Graw Hill Education editora:- NY, 8 ed. p.153- $183,2013$.

LEME, D. M.; PRIMO, F. L.; GOBO, G. G.; COSTA, C. R. V.; TEDESCO, A. C.; OLIVEIRA, D. P.. Genotoxicity assessment of reactive and disperse textile dyes using human dermal equivalente (3D cell culture system). Journal of Toxicology Environmental Health A, Philadelphia, v. 78, n. 7, p. 466-480, 2015.

LI, C-L.; TIAN, T.; NAN, K-J.; ZHAO, N.; ZHANG, W-G. Survival advantages of multicellular spheroids vs. monolayers of HepG2 cells in vitro. Oncology Reports, Athens, v. 20, p.1465-1471, 2008.

LI, N.; SHANG, L.; WANG, S. C.; LIAO, L. S.; CHEN, D.; HUANG, J. F.; XIONG, K.; The toxic effect of ALLN on primary rat retinal neurons. Neurotoxicity Research, New York, v. 30, n.3, p.392-406, 2016. 
LI, N.; LIU, Y.; QIU, J.; ZHONG, L.; ALÉPÉE, N.; COTOVIO, J.; CAI, Z. In vitro skin irritation assessment becomes a reality in China using a reconstructed human epidermis test method. Toxicology in Vitro, Oxford, v. 41, p. 159-167, 2017.

LIANG, T.; XU, X.; YE, D.; CHEN, W.; GAO, B.; HUANG, Y. Caspase/AIF/ apoptosis pathway: a new target of puerarin for diabetes mellitus therapy. Molecular Biology Reports, Netherlands, p. 1-11, 2019, DOI: https://doi.org/10.1007/s11033-019-04925-1.

LIU, Y.; LU. T.; ZHOU, Z.; ZHANG, Y. Study on feasibility of HaCaT epidermal model as an alternative to skin irritation in vitro. Chinese journal of reparative and reconstructive surgery, Ontario, v.31, n. 10, p. 1262-1266, 2017.

LO, H-M.; MA, M-C.; SHIEH, J-M.; CHEN, H-L.; WU, W-B. Naked physically synthetized gold nanoparticles affect migration, mitocondrial activity, and proliferation of vascular smooth muscle cells. International Journal of Nanomedicine, Albany, v. 13, p. 3163-3173, 2018.

LOURENÇÃO, P. L. T. A.; QUEIROZ, D. S.; OLIVEIRA JUNIOR, W. E.; GOMES, G. T.; MARQUES, R. G.; JOZALA, D. R.; ORTOLAN, E. V. P. Tempo de observação e resolução espontânea de fimose primária em crianças. Revista do Colégio Brasileiro de Cirurgiões, v.44, n.5, p.505-510, 2017.

LORENZO, Y.; COSTA, S.; COLLINS, A. R.; AZQUETA, A. The comet assay, DNA damage repair and cytoxicity: hedgehogs are not always dead. Mutagenesis, Dordrecht, v. 28, n. 4, p. 427-432, 2013.

LOUHIMIES, S. Directive 86/609/EEC on the protection of animals used for experimental and other scientific purposes. ATLA- Alternative to Laboratory Animals, England, v. 30, n.2, p.217-219, 2002.

LOVELL, D. P.; OMORI, T. Statistical issues in the use of the comet assay. Mutagenesis, Oxford, v.23, n.3, p.171-182, 2008.

MADNANI, N.; KHAN, K. Symposium-hair disorders. Indian Journal of Dermatology, Venerology \& Leprology, Mumbai, v. 79, n. 5, p.654-667, 2013.

MAJTNEROVÁ, P.; ROUŠAR, T. An overview of apoptosis assays detecting DNA fragmentation. Molecular Biology Reports, Dordrecht, v. 45, n. 5, p.1469-1478, 2018.

MARIE, C.; MAITRE, A.; DOUKI, T.; GATEAU, M.; TARANTINI, A.; GUIRAUD, P.; FAVIER, A.; RAVANAT, J-L. Influence of the metabolic properties of human cells on the kinetic of formation of the major benzo[a]pyrene DNA adducts. Journal of Applied Toxicology, England, v. 28, p.579-590, 2008.

MATHES, S. H.; RUFFNER, H.; GRAF-HAUSNER, U. The use of skin model in drug development. Advanced Drug Delivery Reviews, Amsterdam, v.69, p.81-102, 2014.

MAZZOLENI, G.; LORENZO, D.; STEIMBERG, N. Modelling tissues in 3D: the next future of pharmaco-toxicology. Genes and Nutrition, v. 4, p. 13-22, 2009.

MEWES, K. R.; FISCHER, A.; ZÖLLER, N. N.; LAUBACH, V.; BERND, A.; JACOBS, A.; ROMPAY, A.; LIEBSCH, M.; PIROW, R.; PETERSOHN, D. Catch-up validation study of an 
in vitro skin irritation test method based on an open source reconstructed epidermis (phase I). Toxicology in Vitro, Oxford, v.36, p.238-253, 2016.

MILAN, E. C.; RIEDER, E. A. An approach to cosmeceuticals. Journal of Drugs in Dermatology, New York, v. 15, n. 4, p. 452-456, 2016.

MOHIT, R.; KUJUR, P. K.; MISHRA, A.; SINGH, R. P. Flavonoids inhibit chronically exposed arsenic-induced proliferation and malignant transformation of $\mathrm{HaCaT}$ cells. Photodermatology, Photoimmunology \& Photomedicine, Malden, v. 34, n.1, p. 91-101, 2018.

MOLL, R.; DIVO, M.; LANGBEIN, L. The human keratins: biology and pathology. Histochemistry and Cell Biology, Germany, v. 129, p. 705-733, 2008.

MORALES, M.; PÉREZ, D.; CORREA, L.; RESTREPO, L. Evaluation of fibrina-based dermal-epidermal organotypic cultures for in vitro skin corrosion and irritation testing chemical according OECD TG 431 and 439. Toxicology in Vitro, Oxford, v. 36, 89-96, 2016.

MOSMANN, T. Rapid colorimetric assay for cellular growth and survival: application to proliferation and citotoxicity assays. Journal of Immunological Methods, Amsterdam, v.65, p. 55-63, 1983.

NATIONAL CANCER INSTITUTE. Hair dyes and cancer risk. 2016. Disponível em: < http://www.cancer.gov/cancertopics/causes-prevention/risk-factors/myths/hair-dyes-fact-sheet $>$ Acesso em: 25 Maio 2020.

NOHYNEK, G. J.; ANTIGNAC, E.; RE, T.; TOUTAIN, H. Safety assessment of personal care products/ cosmetics and their ingredients. Toxicology and Applied Pharmacology, San Diego, v.243, p.239-259, 2010.

ORGANISATION FOR ECONOMIC CO-OPERATION AND DEVELOPMENT. Test no. 406. Skin sensitization. Adopted by the council $17^{\mathrm{TH}}$ july 1992. 1992. Disponível em: < https://www.oecd-ilibrary.org/docserver/9789264070660-

en.pdf?expires $=1587781559 \& \mathrm{id}=\mathrm{id} \&$ accname $=$ guest $\&$ checksum $=\mathrm{CE} 1 \mathrm{E} 0 \mathrm{D} 1913 \mathrm{~B} 461 \mathrm{FB} 651$

AD49C8F26BD8B >. Acesso em 24 Abr. 2020.

ORGANISATION FOR ECONOMIC CO-OPERATION AND DEVELOPMENT. ENV/JM/MONO(2005)14. OECD series on testing and assessment number 34. Guidance document on the validation and international acceptance of new or updated test methods for hazard assessment. 2005. Dísponível em: https://ntp.niehs.nih.gov/iccvam/suppdocs/feddocs/oecd/oecd-gd34.pdf>. Acesso em 24 Abr. 2020.

ORGANISATION FOR ECONOMIC CO-OPERATION AND DEVELOPMENT. Test no. 429. Skin sensitization: local lymph node assay. 2010. Disponível em: < https://ntp.niehs.nih.gov/iccvam/suppdocs/feddocs/oecd/oecd-tg429-2010.pdf >. Acesso 24 Abr. 2020.

ORGANISATION FOR ECONOMIC CO-OPERATION AND DEVELOPMENT. Test $\mathbf{n}^{\mathbf{0}}$. 404. Acute dermal irritation/corrosion. 2015a. Disponível em: < https://read.oecdilibrary.org/environment/test-no-404-acute-dermal-irritation-corrosion_9789264242678en\#page1>> Acesso em 10 Mar. 2020. 
ORGANISATION FOR ECONOMIC CO-OPERATION AND DEVELOPMENT. Test $\mathbf{n}^{\mathbf{0}}$. 430. In vitro skin corrosion: transcutaneous electrical resistance test method (TER). 2015b. Disponível em: < https://www.oecd-ilibrary.org/environment/test-no-430-in-vitro-skincorrosion-transcutaneous-electrical-resistance-test-method-ter_9789264242739-en >. Acesso em 02 Maio 2020.

ORGANISATION FOR ECONOMIC CO-OPERATION AND DEVELOPMENT. Test no. 435. In vitro membrane barrier test method for skin corrosion. 2015c. Disponível em: < https://www.oecd-ilibrary.org/docserver/9789264242791-

en.pdf?expires $=1587780473 \& \mathrm{id}=\mathrm{id} \&$ accname$=$ guest $\&$ checksum=7B82115700067D74E1D2 7C7A0663B764> Acesso em 24 Abr. 2020.

ORGANISATION FOR ECONOMIC CO-OPERATION AND DEVELOPMENT. ENV/JM/MONO(2015)26. Joint meeting of the chemicals committee and the working party on chemical, pesticides and biotechnology. Performance standards for the assessment of proposed similar or modified in vitro reconstructed human epidermis (RHE) test methods for skin corrosion testing as described in TG 431. 2015d. Disponível em: < http://www.oecd.org/officialdocuments/publicdisplaydocumentpdf/?cote=ENV/JM/MONO(2 015)26\&doclanguage=en >. Acesso em 10 Mar. 2020.

ORGANISATION FOR ECONOMIC CO-OPERATION AND DEVELOPMENT. ENV/JM/MONO(2015)27. Joint meeting of the chemicals committee and the working party on chemical, pesticides and biotechnology. Performance standards for the assessment of proposed similar or modified in vitro reconstructed human epidermis (RHE) test methods for skin irritation testing as described in TG 439. 2015e. Disponível em: < http://www.oecd.org/officialdocuments/publicdisplaydocumentpdf/?cote=ENV/JM/MONO $(2$ 015) $27 \&$ doclanguage $=\mathrm{en}>$. Acesso em 10 Mar. 2020.

ORGANISATION FOR ECONOMIC CO-OPERATION AND DEVELOPMENT. Test $\mathbf{n}^{\mathbf{*}}$. 489. In vivo mammalian alkaline comet assay. 2016. Disponível em: < https://www.oecdilibrary.org/docserver/9789264264649-

ORGANISATION FOR ECONOMIC CO-OPERATION AND DEVELOPMENT. Test no. 402. Acute dermal toxicity: fixed dose procedure. 2017. Disponível em: < https://www.oecdilibrary.org/docserver/9789264070585-

en.pdf?expires $=1587781028 \& i d=i d \& a c c n a m e=$ guest $\&$ checksum $=12 C 5 D 5 E 5 F 8 A 472835 D 44$ F7B893472EBF >. Acesso em 24 Abr. 2020.

ORGANISATION FOR ECONOMIC CO-OPERATION AND DEVELOPMENT. Test no. 439. In vitro skin irritation: reconstructed human epidermis test method. 2019a. Disponível em: $<\quad$ https://www.oecd-ilibrary.org/environment/test-no-439-in-vitro-skin-irritationreconstructed-human-epidermis-test-method_9789264242845-en > Acesso em: 29 Out. 2019.

ORGANISATION FOR ECONOMIC CO-OPERATION AND DEVELOPMENT. Test no. 431. In vitro skin corrosion: reconstructed human epidermis (RHE) test method. 2019b. Disponível em: < https://www.oecd-ilibrary.org/environment/test-no-431-in-vitro-skincorrosion-reconstructed-human-epidermis-rhe-test-method_9789264264618-en > Acesso em 10 Nov. 2019.

PARK, E.; LEE, G.; SHIM, J.; CHO, M.; LEE, B.; KIM, Y.; KIM, J.; KIM, Y.; KIM, D. Comparison of the toxicity of aluminum oxide nanorods with different aspect ratio. Archieves of Toxicology, New York, v.89, p.1771-1782, 2015. 
PEDROSA, T. N.; CATARINO, C. M.; PENNACCHI, P. C.; ASSIS, S. R.; GIMENES, F.; CONSOLARO, M. E. L.; BARROS, S. B. M.; MARIA-ENGLER, S. S. A new reconstructed human epidermis (RHE) for in vitro skin irritation testing. Toxicology In Vitro, Oxford, v.42, p.31-37, 2017.

PINA, C. José de Alencar; Guia Estudo. 2019. Disponível em < https://www.guiaestudo.com.br/jose-de-alencar >. Acesso em: 18 Maio 2020.

POUMAY, Y.; DUPONT, F.; MARCOUX, S.; LECLERCQ-SMEKENS, M.; HÉRIN, M.; COQUETTE, A. A simple reconstructed human epidermis: preparation of the culture model and utilization in in vitro studies. Archieves of Dermatological Research, Germany, v. 296, p.203-211, 2004.

POUMAY, Y.; COQUETTE, A. Modelling the human epidermis in vitro: tools for basic and applied research. Archives of Dermatological Research, Germany, v. 298, p. 361-369, 2007.

PRAY, L. A. DNA replication and causes of mutation. Nature Education, v. 1, n. 1, p. 214, 2008. Disponível em: < https://www.nature.com/scitable/topicpage/dna-replication-andcauses-of-mutation-409/ > . Acesso em: 27 Maio 2020.

PRESGRAVE, O. A. F. The need for the establishment of a Brazilian centre for the validation of alternative methods (BraCVAM). ATLA, New York, v. 36, p.705-708, 2008.

RADHIKA, P.; JYOTHI, Y. A review on genotoxicity, its molecular mechanisms, regulatory testing in drug development process. International Journal of Pharmaceutical Sciences and Research, Panchkula, n. 5, p. 4054-4069, 2019.

RAI, Y.; RICHA, P.; KUMARI, N.; SAH, D. K.; PANDEY, S.; KALRA, N.; SONI, R.; DWARAKANATH, B. S.; BHATT, A. N. Mitochondrial biogenesis and metabolic hyperactivation limits the application of MTT assay in the estimation of radiation induced growth inhibition. Scientific Reports, London, v. 9, p. 1-15, 2018.

REISINGER, K.; BLATZ, V.; BRINKMANN, J.; DOWNS, T. R.; FISCHER, A.; HENKLER, F.; HOFFMANN, S.; KRUL, C.; LIEBSCH, M.; LUCH, A.; PIROW, R.; REUS, A. A.; SCHULZ, M.; PFUHLER, S. Validation of the 3D skin comet assay using full thickness skin models: transferability and reproducibility. Mutation Research/Genetic Toxicology and Environmental, Amsterdam, v. 827, p. 27-41, 2018.

REUS, A. A.; REISINGER, K.; DOWNS, T. R.; CARR, G. J.; ZELLER, A.; CORVI, R.; KRUL, C. A. M.; PFUHLER, S. Comet assay in reconstructed 3D human epidermal skin models- investigation of intra- and inter- laboratory reproductibility with coded chemicals. Mutagenesis, Oxford, v.28, n.6, p.709-720, 2013.

RUKWIED, R. Physiology of the scalp. Hautarzt, Alemanha, v. 68, n. 6, p.431-436, 2017.

RUSSELL, W.M.S.; BURCH, R.L. The principles of humane experimental technique. 1959. Disponível em: < http://altweb.jhsph.edu/pubs/books/humane_exp/het-toc >. Acesso em 31 Maio 2020.

SANÍA, A. C.; CARREÑO, A. S. Analysis of cosmetics products. 2007. Amsterdam: Elsevier ed., $487 p$. 
SANTOS-FILHO, E. X.; SILVA, A. C. G.; ÁVILA, R. I.; BATISTA, A. C.; MARRETO, R. N.; LIMA, E. M.; OLIVEIRA, C. M. A.; MENDONÇA, E. F.; VALADARES, M. C. Chemopreventive effects of FITOPROT against 5-fluorouracil- induced toxicity in HaCaT cells. Life Sciences, Oxford, v. 193, p.300-308, 2018.

SCCS/1436/11: Scientific committee on consumer safety (SCCS)opinion on Basic red 51 COLIPA B116 12th plenary meeting of 20 September2011. Disponível em: < http://ec.europa.eu/health/scientific_committees/consumer_safety/docs/sccs_o_067.pdf >. Acesso em: 25 Maio 2020.

SCCS/1537/14. Scientific committee on consumer safety opinion on Basic blue 99 COLIPA C059. Submission III, opinion adopted in 7 th plenary meeting of 23 september 2014. Disponível em: http://ec.europa.eu/health/scientific_committees/consumer_safety/docs/sccs_o_067.pdf >. Acesso em: 25 Maio 2020.

SCCS/1564/15. The SCCS notes of guidance for the testing of cosmetic ingredients and their safety evaluation $9^{\text {th }}$ revision. 2016. Disponível em: < https://ec.europa.eu/health/scientific_committees/consumer_safety/docs/sccs_o_190.pdf >. Acesso em: 28 Abr. 2020.

SCCS/1585/17. Scientific committee on consumer safety opinion on Basic Blue 99 Colipa C059 opinion adopted on 6 june 2017. 2017. Disponível em: < https://ec.europa.eu/health/sites/health/files/scientific_committees/consumer_safety/docs/sccs _o_205.pdf >. Acesso em: 25 Maio 2020.

SCHOOP, V.; FUSENING, N. E.; MIRANCEA, N. Epidermal organization and differentiation of HaCaT keratinocytes in organotypic coculture with human dermal fibroblasts. Journal of Investigative in Dermatology, New York, v. 112, n.3, p. 343-352, 1999.

SCHWEIZER, J.; BOWDEN, P. E.; COULOMBE, P. A.; LANGBEIN, L.; LANE, E. B.; MAGIN, T. M.; MALTAIS, L.; OMARY, M. B.; PARRY, D. A. D.; ROGERS, M. A.; WRIGHT, M. W. New consensus nomenclature for mammalian keratins. Journal of Cell Biology, New York, v. 174, n.2, p. 169-174, 2006.

SMEDEN, J. V.; BOUWSTRA, J. A. Stratum corneum lipids: their role for the skin barrier function in healthy subjects and atopic dermatitis patients. Current Problems in Dermatology, Switzerland, v.49, p.8-26, 2016.

SOCIEDADE BRASILEIRA DE UROLOGIA. Cirurgia peniana: fimose e hipospádia. 2006. Disponível em: < https://diretrizes.amb.org.br/_BibliotecaAntiga/cirurgia-peniana-fimose-ehipospadia.pdf > Acesso em: 25 Maio 2020.

SUN, T.; JACKSONA, S.; HAYCOCK, J. W.; MACNEIL, S. Culture of skin cells in 3D rather than 2D improves their ability to survive exposure to cytotoxic agents. Journal of Biotechnology, Amsterdam, v.122, p.372-381, 2006.

TAN, J. J. Y.; COMMON, J. E.; WU, C.; HO, P. C. L.; KANG, L. Keratinocytes maintains compartimentalization between dermal papilla and fibroblasts in 3D heterotypic tri cultures. Cell Proliferation, Hoboken, v. 52, n.5, p. 1-11, 2019. 
TARFUT-CARDONA, Y.; SUARES-ROCHA, P.; FERNANDES, T. C. C.; MARINMORALES, M. A. Cytotoxic and genotoxic effects of two hair dyes used in the formulation of black color. Food and Chemical Toxicology, Oxford, v.86, p.9-15, 2015.

TICE, R. R.; AGURELL, E.; ANDERSON, D.; BURLINSON, B.; HARTMANN, A.; KOBAYASHI, H.; MIYAMAE, Y.; ROJAS, E.; RYU, J. C.; SASAKI, Y. F. Single cell gel/comet assay: guidelines for in vitro and in vivo genetic toxicology testing. Environmental and Molecular Mutagenesis, Hoboken, v.35, p.206-221, 2000.

TURAN-ZITOUNI, G.; YURTTAŞ, L.; TABBI, A.; ÇIFTÇI, G. A.; TEMEL, H. E.; KAPLANCIKLI, Z. A. New thiazoline-tetralin derivatives and biological activity evaluation. Molecules, Switzerland, v.23, n.135, p.1-15, 2018.

UNITED NATIONS. GLOBALLY HARMONIZED SYSTEM OF CLASSIFICATION AND LABELLING OF CHEMICAL (GHS). 8th revised edition. 2018. Available in: < https://www.unece.org/fileadmin/DAM/trans/danger/publi/ghs/ghs_rev08/ST-SG-AC10-30Rev8e.pdf > . Access on Mar 10, 2020.

VENUS, M.; WATERMAN, J.; McNAB, I. Basic physiology of the skin. Surgery, New York, v. 29, n. 10, p. 471-474, 2011.

VINEIS, P.; PIRASTU, R. Aromatic amines and cancer. Cancer Causes \& Control, Dordrecht, v.8, n.3, p.346-355, 1997.

WARD, E. M.; SABBIONI, G.; DE BORD, D.G.; TEASS, A.W.; BROWN, K. K.; TALASKA, G. G.; ROBERTS, D.R.; RUDER, A.M.; STREICHER, R.P. Monitoring of aromatic amine exposures in workers at a chemical plant with a known bladder cancer excess. Journal of the National Cancer Institute, Cary, v.88, n.15, p.1046-1052 ,1996.

WASHIO, K.; IJUIN, K.; FUKUNAGA, A.; NAGAI, H.; NISHIGORI, C. Contact anaphylaxis caused by basic blue 99 in hair dye. Contact Dermatitis, Malden, v. 77, p. 116-123, 2017.

WATSON, J. D.; CRICK, F. H. C. Molecular structure of nucleic acids: a structure for deoxyribose nucleic acid. Nature, London, v. 171, p. 737-738, 1953

WEYERMANN, J.; LOCHMANN, D.; ZIMMER, A.; A pratical note on the use of cytotoxicity assays. International Journal of Pharmaceutics, Amsterdam, v. 288, n.2, v. 369-376, 2005.

WHITAKER, R. M.; CORUM, D.; BEESON, C. C.; SCHNELLMANN, R. G. Mitochondrial biogenesis as a pharmacological target: a new approach to acute and chronic diseases. Annual Review of Pharmacology and Toxicology, Palo Alto, v. 56, p.229-249, 2016.

WORLD HEALTH ORGANIZATION. WHO guidelines on hand hygiene in health care. 2009. Disponível em: < http://www.who.int/gpsc/5may/tools/9789241597906/en/ > Acesso em 25 Maio 2020.

YOUSEF, H.; ALHAJJ, M.; SHARMA, S. Anatomy, skin (intergument), epidermis, 2017. Disponível em: < https://www.ncbi.nlm.nih.gov/books/NBK470464/\#_NBK470464_pubdet_> Acesso em 25 Set. 2020.

ZANONI, T.B.; TIAGO, M.; FAIÃO-FLORES, F.; BARROS, S.B. de M.; BAST, A.; HAGEMAN, G.; OLIVEIRA, D.P. de; MARIA-ENGLER, S.S. Basic red 51, a permited semi- 
permanent hair dye, is cytotoxic to human keratinocytes (HaCaT). Toxicology Letters, Clare, v.227, p.139-149, 2014.

ZANONI, T. B.; HUDARI, F.; MUNNIA, A.; PELUSO, M.; GODSCHALK, R. W.; ZANONI, M. V. B.; DEN HARTOG, G. J. M.; BARROS, S. B. M.; MARIA-ENGLER, S. S.; HAGEMAN, G. J.; OLIVEIRA, D. P. The oxidation of p-phenylenediamine, na ingrediente used for permanente hair dyeing purposes, leads to the formation of hidroxyl radicals: oxidative stress and DNA damage in human immortalized keratinocytes. Toxicology Letters, Clare, v.239, p.194-204, 2015.

ZANONI, T. B.; PEDROSA, T. N. CATARINO, C. M.; SPIEKSTRA, S. W.; OLIVEIRA, D. P.; HARTOG, G. D.; BAST, A.; HAGEMANN, G.; GIBBS, S.; BARROS, S. B. M.; MARIAENGLER, S. S. Allergens of permanente hair dyes induces epidermal damage, skin barrier loss IL-1 $\alpha$ increase in epidermal in vitro model. Food and Chemical Toxicology, Oxford, v. 112, p. 265-272, 2017.

ZHOU, T.; HU, Y.; WANG, Y.; SUN, C.; ZHONG, Y.; LIAO, J.; WANG, G. Fine particulate matter (PM 2.5) aggravates apoptosis of cigarette-inflamed bronchial epithelium in vivo and in vitro. Environmental Pollution, Oxford, v. 248, p. 1-9, 2019. 
ANEXOS 


\section{ANEXO}

Anexo A- Comprovação da submissão do artigo

\section{Track your co-authored submission to Chemico-Biological Interactions}

Chemico-Biological Interactions <EviseSupport@elsevier.com>

Responder a: EviseSupport@elsevier.com

Para: camilaamini@gmail.com

\section{Dear Mrs Mini,}

Submission no: CHEMBIOINT_2020_873

Submission title: IMMORTALIZEED EQ̄UIVALENT HUMAN EPIDERMIS AS A PLATFORM TO EVALUATION HAIR DYES TOXICITY: EFFICIENCY COMPARISON BETWEEN 3D AND MONOLAYER CULTURE

Corresponding author: Professor Danielle Palma de Oliveira

Listed co-author(s): Mrs Camila Mini, Dr Daniel Dorta, Dr Silvya Stuchi Maria-Engler

Professor Palma de Oliveira has submitted a manuscript to Chemico-Biological Interactions and listed you as a coauthor. This email is to let you know we will be in contact with updates at each decision stage of the submission process.

The link below takes you to a webpage where you can sign in to our submission system using your existing Elsevier profile credentials or register to create a new profile. You will then have the opportunity to tailor these updates and view reviewer and editor comments once they become available.

http://www.evise.com/profile/api/navigate/CHEMBIOINT?resourceUrl=\%2Fco-author\%2F\%3Fdgcid\%3Dinvite_email_ coauthoroutreach00092797\%23\%2FCHEMBIOINT\%2Fsubmission\%2FCHEMBIOINT_2020_873\&email= camilaamini@gmail.com\&firstName=Camila\&surname=Mini\&country=Brazil\&institution=Faculty+of+Pharmaceutical+ Sciences+of+Ribeir\%C3\%A3o+Preto-+Laboratory+of+Ecotoxicology+and+Human+ Toxicology $\% 2 \mathrm{C}+$ University+of+S\%C3\%A3o+Paulo\&title=Mrs

If you are not a co-author of this manuscript, please contact Researcher Support at: https://service.elsevier.com Thank you very much for your submission and we will be in touch as soon as we have any news to share.

Chemico-Biological Interactions

If you do not wish to receive further update emails on your co-authored submission, you can unsubscribe via this link: 